\title{
Osteology of Batrachuperus londongensis (Urodela, Hynobiidae): study of bony anatomy of a facultatively neotenic salamander from Mount Emei, Sichuan Province, China
}

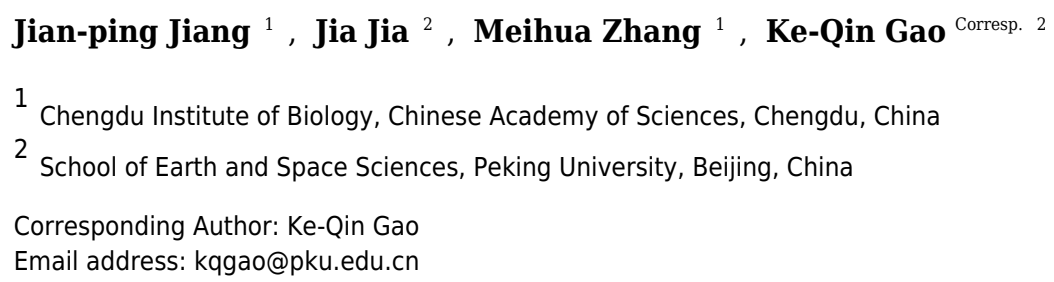

The Longdong Stream Salamander Batrachuperus londongensis, living in a mountain stream environment at Mt. Emei in Sichuan Province, China, represents a rare species that is facultatively neotenic in the family Hynobiidae. Although the species has been known to science for some 40 years since its initial discovery in the late 1970s, anatomical details of its osteology remain poorly understood and developmental information is still lacking for the species. This study 1 ) provides a detailed osteological account of $B$. londongensis based on micro-CT scanning and clearing and staining of multiple specimens from the type locality; 2) provides a discussion of intraspecific variation related to life-history differences; and 3) presents a discussion on limb features related to morphological evolution of limb patterns correlative with ecological adaptation to mountain stream environments. Osteological comparisons with congeneric species has led to recognition of several diagnostic features that are unique to $B$. londongensis, including: vomers widely separated from one another, lacking a midline contact; presence of uncommon perichondral ossification of the ascending process of the palatoquadrate as part of the suspensorium; and presence of a prominent posterodorsal process of the scapular blade, which serves as a ligamentous insertion of the levator muscle of the scapula. In addition, some but not all neotenic individuals retain the palatine as a discrete element, indicative of its delayed absorption after sexual maturity. Postmetamorphic and neotenic individuals are strikingly different in the complexity of hyobranchial structures. Neotenes display a high degree of ossification of hyobranchial elements, tend to increase ossification of both hypobranchial I and ceratobranchial I during aging, and retain fully ossified ceratobranchial III and IV; in contrast, these elements remain entirely cartilaginous or are totally lost by resorption in postmetamorphic individuals. In addition, all postmetamorphic forms display an inverted "T"-shaped basibranchial II, whereas neotenes show transformation from a "fork"-shaped 
to the " $\mathrm{T}$ "-shaped configuration after sexual maturity. Batrachuperus londongensis displays a mosaic of apomorphic and plesiomorphic states in its limb ossifications: presence of a single centrale element in both the manus and pes is a derived condition in Hynobiidae and other families as well, whereas retention of a postminimus in the pes is obviously plesiomorphic within Urodela. Reduction in number of digits from five to four in the pes and possession of a cornified sheath covering the terminal phalanges are also derived features shared with some but not all mountain stream salamanders that are adapted to a similar type of environment. 
2 Osteology of Batrachuperus londongensis (Urodela,

3 Hynobiidae): study of bony anatomy of a facultatively

4 neotenic salamander from Mount Emei, Sichuan Province,

5 China

6

7 Jian-ping Jiang ${ }^{1}$, Jia Jia ${ }^{2}$, Meihua Zhang ${ }^{1}$, Ke-Qin Gao ${ }^{2}$

$8 \quad{ }^{1}$ Chengdu Institute of Biology, Chinese Academy of Sciences, Chengdu 610041, China

$9 \quad{ }^{2}$ School of Earth and Space Sciences, Peking University, Beijing 100871, China

10

11

12 Corresponding authors: Ke-Qin Gao, 5 Yiheyuan Road, Beijing 100871, China

13 Email address: kqgao@pku.edu.cn

14

15 


\section{Abstract}

18 The Longdong Stream Salamander Batrachuperus londongensis, living in a mountain stream

19 environment at Mt. Emei in Sichuan Province, China, represents a rare species that is

20 facultatively neotenic in the family Hynobiidae. Although the species has been known to science

21 for some 40 years since its initial discovery in the late 1970s, anatomical details of its osteology

22 remain poorly understood and developmental information is still lacking for the species. This

23 study 1) provides a detailed osteological account of $B$. londongensis based on micro-CT scanning

24 and clearing and staining of multiple specimens from the type locality; 2) provides a discussion

25 of intraspecific variation related to life-history differences; and 3) presents a discussion on limb

26 features related to morphological evolution of limb patterns correlative with ecological

27 adaptation to mountain stream environments. Osteological comparisons with congeneric species

28 has led to recognition of several diagnostic features that are unique to $B$. londongensis, including:

29 vomers widely separated from one another, lacking a midline contact; presence of uncommon

30 perichondral ossification of the ascending process of the palatoquadrate as part of the

31 suspensorium; and presence of a prominent posterodorsal process of the scapular blade, which

32 serves as a ligamentous insertion of the levator muscle of the scapula. In addition, some but not

33 all neotenic individuals retain the palatine as a discrete element, indicative of its delayed

34 absorption after sexual maturity. Postmetamorphic and neotenic individuals are strikingly

35 different in the complexity of hyobranchial structures. Neotenes display a high degree of

36 ossification of hyobranchial elements, tend to increase ossification of both hypobranchial I and

37 ceratobranchial I during aging, and retain fully ossified ceratobranchial III and IV; in contrast,

38 these elements remain entirely cartilaginous or are totally lost by resorption in postmetamorphic 
39 individuals. In addition, all postmetamorphic forms display an inverted "T"-shaped

40 basibranchial II, whereas neotenes show transformation from a "fork"-shaped to the "T"-shaped

41 configuration after sexual maturity. Batrachuperus londongensis displays a mosaic of

42 apomorphic and plesiomorphic states in its limb ossifications: presence of a single centrale

43 element in both the manus and pes is a derived condition in Hynobiidae and other families as

44 well, whereas retention of a postminimus in the pes is obviously plesiomorphic within Urodela.

45 Reduction in number of digits from five to four in the pes and possession of a cornified sheath

46 covering the terminal phalanges are also derived features shared with some but not all mountain

47 stream salamanders that are adapted to a similar type of environment.

\section{Introduction}

50 The family Hynobiidae includes 66-67 species in 9-11 genera (Fei et al., 2006; AmphibiaWeb,

51 2017; Frost, 2017). These are small to medium sized salamanders found primarily in Asia,

52 although geographical range of one species (the Siberian Salamander Salamandrella

53 keyserlingii) extends from Asia into European Russia (AmphibiaWeb, 2017; Frost, 2017).

54 Phylogenetically, the Hynobiidae form the sister clade with Cryptobranchidae, the two families 55 together classified in the suborder Cryptobranchoidea Dunn, 1922. The Hynobiidae have long 56 been viewed as a group of primitive salamanders, as they lack derived features such as fusion of

57 the angular with the prearticular in the lower jaw, but retain plesiomorphic features, including 58 external fertilization (Dunn, 1923; Noble, 1931), a large number of chromosomes (2n=40-78), 59 and the presence of microchromosomes (Morescalchi, 1973, 1975; Edwards, 1976; Sessions, 60 2008).

61 Based on the fossil record from northern China, the evolutionary history of the 
62 Hynobiidae can be traced back to Aptian time ( $\sim 125 \mathrm{Ma})$ during the Early Cretaceous (Chen \&

63 Gao, 2009; Gao, Chen \& Jia, 2013; Jia \& Gao, 2016b). Several extinct taxa from China

64 including Liaoxitriton and Nuominerpeton are apparently stem-group hynobiids, as evidenced by

65 their possession of derived features shared with extant hynobiids, including: transverse and

66 arched vomerine tooth rows; a deeply notched posterolateral border of the vomer for choana; and

67 an optic foramen opening at the notched posterior border of orbitosphenoid (Chen \& Gao, 2009;

68 Gao, Chen \& Jia, 2013; Jia \& Gao, 2016a). The fossil record indicates that the split of the

69 hynobiid from cryptobranchid clade seems to be a phylogenetic event that had taken place no

70 later than the Aptian time ( $\sim 125 \mathrm{Ma})$. Recent analyses of the nuclear exon and mitochondrial

71 genome estimate the Cryptobranchidae-Hynobiidae split as $\sim 150 \mathrm{Ma}$ and the origin of crown-

72 group hynobiids as $\sim 125 \mathrm{Ma}$ (Zheng et al., 2011: fig. 3). A more recent analysis of nuclear

73 genes, however, yielded an estimate of $\sim 157$ Ma for the split and $\sim 135 \mathrm{Ma}$ for the origin of

74 crown-group hynobiids (Chen et al., 2015: fig. 2).

75

Most hynobiids are terrestrial in the adult stage, but species in several genera

76

77

78

79

80

81

82

83

84

(Batrachuperus, Liua, Pachyhynobius, Ranodon and Paradactylodon) are mostly mountain

stream dwellers that can be found in water all year around (Reilly, 1983; Fei et al., 2006;

Sparreboom, 2014; AmphibiaWeb, 2017). In terms of life-history features, most hynobiids have a biphasic life cycle, with a gilled aquatic larval stage going through metamorphosis to a postmetamorphic adult stage. The exception is the Japanese species Hynobius retardatus, which has been reported as partly neotenic as a population variant from Lake Kuttarush in Hokkaido, with some specimens reaching a total length of $150 \mathrm{~mm}$ while retaining gills (Sasaki, 1924). However, this population now appears to be extinct, with no osteological description of the population ever undertaken (Inukai, 1930-1932; Wakahara, 1996). Accordingly, Batrachuperus 
85 londongensis Liu \& Tian, 1978, commonly known as the Longdong Stream Salamander, appears

86 to be the only extant hynobiid species that has been documented as facultatively neotenic (Fei et

87 al., 2006). Osteological study of this unusual hynobiid is bound to be significant for

88 understanding patterns of ossification of the cranium and post-cranium, and for reconstruction of

89 the evolution of hynobiid salamanders more generally. Furthermore, such an osteological study

90 is in urgent need because survival of the species at the type locality Longdong Stream is facing a

91 severe threat from habitat destruction and illegal collection (see below).

92 Within Hynobiidae, the genus Batrachuperus includes six or seven species (Fei et al.,

93 2006; Fu \& Zeng, 2008; Fei, Ye \& Jiang, 2010) that are all endemic to western China. The

94 genus consists of the type species Batrachuperus pinchonii (David, 1872) plus five other species

95 (B. londongensis, B. tibetanus, B. yenyuanensis, B. taibaiensis, and B. karlschmidti; see Fei et al.,

96 2006; Fu \& Zeng, 2008). Another nominal taxon, Batrachuperus cochranae Liu, 1950, was

97 synonymized with Batrachuperus pinchonii based on molecular evidence (Fu \& Zeng, 2008), but

98 the validity of the name is still in dispute (Fei, Ye \& Jiang, 2010, 2012). All of these are aquatic

99 forms that inhabit mountain stream and/or plateau pond environments, at elevations ranging from

$1001200 \mathrm{~m}-4400 \mathrm{~m}$ above sea level (Fei et al., 2006; Fei, Ye \& Jiang, 2010). In terms of

101 conservation status, most of these species are currently vulnerable (Jiang et al., 2016). No

102 fossil record has been found for Batrachuperus or its sister clade (Liua + Pseudohynobius).

103 Based on molecular data alone, Batrachuperus was estimated as having originated in the late

104 Miocene ( 7.3 Ma) in a recent analysis using 29 nuclear genes (Chen et al., 2015), a much

105 younger date than the estimation of $\sim 24.3$ Ma based on the complete mitochondrial genome

106 (Zhang et al., 2006) or that of 20-30 Ma based on complete mitochondrial genome and three

107 nuclear genes (Zheng et al., 2011). 
109 Pachyhynobius, Paradactylodon, Pseudohynobius) that have received little study of their

110 developmental osteology (Rose, 2003); moreover, anatomical details remain poorly known for

111 these taxa. For the genus Batrachuperus, brief osteological accounts of the type species, $B$.

112 pinchonii can be found in the literature (e.g., Zhang et al., 2009; Xiong et al., 2013a); however,

113 adequate osteological description of $B$. londongensis is still lacking, although the species has

114 been known to science for almost 40 years since its discovery in the late $1970 \mathrm{~s}$. In regard to

115 phylogenetic relationships, few adequate data can be found in the literature on osteological

116 details of the species. Attempting to improve this awkward situation, our study provides a

117 detailed osteological account of $B$. londongensis and a morphological comparison in relation to

118 life-history differences within this species; in addition, we present a discussion on diagnosis of

119 the species based on bony features, patterns of ossification of the hyobranchium and limb

120 ossification. Phylogenetic analysis will be performed in future research when necessary data

121 becomes available for other congeneric species.

122

\section{Materials \& Methods}

124 A total of 12 specimens of Batrachuperus londongensis were used in this study, including both

125 juvenile (1) and adults (11), and both postmetamorphic (4) and neotenic (8) individuals (Table

126 1). The material used includes both dry skeletons and fluid-preserved ( $10 \%$ formaldehyde)

127 specimens. In addition, cleared and stained specimens (CIB 14499, 14504) allowed observation

128 of both bony and cartilaginous structures. All of these specimens are deposited in the Chengdu

129 Institute of Biology (CIB), Chinese Academy of Sciences, Chengdu, China. For purpose of

130 comparison, several specimens belonging to congeneric species and other hynobiid species were 
131 used in this study (see Table S1).

132 Total length (TL) refers to the measurement between the tip of the snout and the posterior

133 extremity of the tail; snout-pelvic length (SPL) is the measurement from the tip of the snout to

134 the posterior end of the pelvis (marked by the anus in fluid-preserved specimens and by the

135 haemal arch of the last caudosacral in dry skeletons). Skull length (SKL) refers to the maximum

136 dimension from the tip of the snout to the posterior end of the occipital condyles; skull width

137 (SKW) is the distance measured between the cranio-mandibular joints. All measurements are in

138 millimeters (mm). Anatomical nomenclature follows Francis (1934), Reilly \& Lauder (1988),

139 and Shubin \& Wake (2003), with the exceptions as noted in several cases.

140 The type specimen of Batrachuperus londongensis is a large male, with a TL of $265 \mathrm{~mm}$

141 and a SPL of $129 \mathrm{~mm}$ (Fig. 1). The specimen carries a field number CIB 65I0013 as in previous

142 publications (e.g., Fei, Ye \& Tian, 1983; Fei et al., 2006), but it has been formally catalogued as

143 CIB 65I0013/14380 in specimen collections at the Chengdu Institute of Biology (Fig. 1). This

144 specimen represents a neotenic form as it retains gill slits and a larval type of hyobranchium (Fei,

145 Ye \& Tian, 1983; Fei et al., 2006). The specimen was collected on March 23, 1965 from the

146 type locality, Longdong Stream at Mount Emei (Emeishan), at an elevation of $1300 \mathrm{~m}$ above sea

147 level as has been documented in the literature (Liu \& Tian, 1978; Fei, Ye \& Tian, 1983).

148 Subsequent collections of specimens were made in 2002, 2006, 2014, and 2016 from the same

149 mountain stream by field crews from the Chengdu Institute of Biology (CIB).

150 Selected specimens from the CIB collections (Table 1), including the holotype (CIB

151 65I0013/14380), were CT scanned using a high-resolution X-ray scanner (Quantum GX micro-

152 CT Imaging System, PerkinElmer ${ }^{\circledR}$ ) at the Chengdu Institute of Biology (CIB), Chinese

153 Academy of Sciences. These specimens were scanned along the coronal axis at an image 
154 resolution of 2000 X 2000. Comparative specimens from the FMNH collections were CT

155 scanned at the University of Chicago (PaleoCT Lab) using a dual tube X-ray scanner from GE.

156 Segmentation and three-dimensional reconstruction of the CT images were made by using VG

157 Studio Max 2.2 (Volume Graphics, Heidelberg, Germany).

158

Two specimens (CIB 14504, 14499) were whole-mount cleared and double stained after

159 being scanned. The clearing and staining procedures followed the protocols of Hanken \&

160 Wassersug (1981). Cartilaginous elements were stained in blue using Alcian Blue 8GX and bony

161 structures were stained in red using Alizarin Red, and then were cleared in glycerin $\mathrm{KOH}$

162 solution. Line drawings of skeletal structures were prepared using Adobe Photoshop ${ }^{\circledR}$ CS6

163 software, and are presented as text figures and supplementary figures (Supporting Information).

164

165 Institutional abbreviations - CIB, Chengdu Institute of Biology, Chinese Academy of

166 Sciences, Chengdu, China; FMNH, Field Museum of Natural History, Chicago, USA; MVZ,

167 Museum of Vertebrate Zoology, University of California, Berkeley, USA.

168

169 Anatomical abbreviations - act, acetabulum; adf, anterodorsal fenestra; amf, anteromedial

170 fenestra; an, angular; ar, articular; at, atlas; bb, basibranchial; bc, basale commune; c, centrale;

171 cb, ceratobranchial; ch, ceratohyal; cor, coracoid; corn, cornua; crd, crista dorsalis; crv, crista

172 ventralis; dc, distal carpal; den, dentary; dt, distal tarsal; etr, external trochanter; fe, femur; ftr,

173 femoral trochanter; fi, fibula; fib, fibulare; fr, frontal; glf, glenoid fossa; $\mathbf{h b}$, hypobranchial; hu,

174 humerus; i, intermedium; icf, internal carotid foramen; il, ilium; isc, ischium; lac, lacrimal; lacf,

175 lacrimal foramen; mx, maxilla; na, nasal; obf, obturator foramen; obs, orbitosphenoid; op-ex,

176 opisthotic-exoccipital complex; pa, parietal; pcor, procoracoid; pm, premaxilla; po, 
177 postminimus; pra, prearticular; prf, prefrontal; pro, prootic; ps, parasphenoid; pt, pterygoid;

178 pub, pubis; qu, quadrate; ra, radius; rad, radiale; rl, radial loop; sca, scapulocoracoid; scof,

179 supracoracoid foramen; sm, septomaxilla; sq, squamosal; st, stapes; stf, stapedial foramen; ti,

180 tibia; tib, tibiale; ul, ulna; uln, ulnare; vo, vomer; y, element y; yps, ypsiloid.

181

182

Results

183

\section{Systematics \& Description}

184 Order Urodela Duméril, 1806

185 Suborder Cryptobranchoidea Dunn, 1922

186 Family Hynobiidae Cope, 1859

187 Genus Batrachuperus Boulenger, 1878

188

189 Species Batrachuperus londongensis Liu \& Tian, 1978

190

191 Holotype. CIB 65I0013/14380, a male adult with a total length of $265 \mathrm{~mm}$, a snout-vent length

192 of $129 \mathrm{~mm}$. The holotype is a neotenic individual, as it is sexually mature but retains gill slits

193 and a larval type of hyobranchium.

194 Type locality. Longdong Stream (N29³4'42.85"/E10317'5.61"), at an elevation of $1300 \mathrm{~m}$

195 above sea level, Mt. Emei (Emeishan), Sichuan Province, China.

196 Known distribution and habitat. The species was previously thought to be known only from

197 Longdong Stream, a mountain stream associated with the Longdong Cave at $1200 \mathrm{~m}-1300 \mathrm{~m}$

198 above sea level (Fei et al., 2006); however, a molecular systematics study has shown that

199 populations previously identified as B. pinchonii from the nearby Mt. Wawushan in Hongya 
200 County and Mt. Nibashan in Hanyuan County may pertain to B. londongensis (Fu \& Zeng,

201 2008). Based on field observations at the type locality, live individuals of the Longdong Stream

202 Salamander often hide under rock cover in the mountain stream, and they feed on fresh-water

203 shrimp, aquatic insects and insect larvae (Fei, Ye \& Jiang, 2010).

204 Diagnosis. Batrachuperus londongensis can be distinguished from the type species B. pinchonii

205 and all other congeneric species in having a unique combination of the following osteological

206 features: alary process of premaxilla barely contributing to border of anterodorsal fenestra

207 (shared with B. tibetanus); suture between nasal and frontal located at the level of anterior border

208 of orbit; frontal extending far posteriorly, terminating at the level of otic process of pterygoid;

209 vomers widely separated from one another, lacking a midline contact (unique); vomerine teeth

210 four to eight in number, arranged in a straight line that is strongly oblique and nearly vertical in

211 orientation (unique); ascending process of palatoquadrate ossified as a short pillar propping

212 lateral edge of parietal behind orbit (shared with B. karlschmidti and B. taibaiensis); radial loops

213 stemming from basibranchial I not crossing one another; presacral vertebrae 18 in number;

214 scapular blade bearing prominent posterodorsal process, onto which a levator muscle of the

215 scapula inserts (unique); ischial plate is penetrated by a small nerve foramen, and the ischial

216 spine is clearly more elongated than in other species.

217 Taxonomic remarks. In the literature, the species epithet has been confusingly spelled as

218 Batrachuperus londongensis (e.g., Liu \& Tian, 1978; Liu et al., 1978; Fu et al., 2001; Wu \& Xie,

219 2004; Fei et al., 2006; Fei, Ye \& Jiang, 2010, 2012) and Batrachuperus longdongensis (e.g., Liu

220 \& Tian, 1983 in Fei, Ye \& Tian, 1983; Fei \& Ye, 1984; Song et al., 2001). Judging from the

221 published literature regarding the two available names differing in spelling, it is clear that the

222 former is valid and the latter invalid owing to its status as a "nomen nudum" (Fei et al., 2006). 
224 Tian (1978) in Liu et al. (1978). The year before this publication, the same authors (Liu \& Tian, 225 1977) first published the species name spelled as "Batrachuperus longdongensis" in a systematic 226 checklist of Chinese amphibians (Laboratory of Amphibians and Reptiles, Biological Institute of 227 Sichuan Province, 1977) without a type designation, description, or illustration (see ICZN, 1999: 228 art. 13); for that reason, the name "Batrachuperus longdongensis" Liu \& Tian, 1977 is 229 considered a nomen nudum (Fei et al., 2006). Unfortunately, Liu \& Tian (1983, in Fei, Ye \& 230 Tian, 1983) "re-published" the invalid name "Batrachuperus longdongensis" and labeled it as a 231 new species. Although the latter publication provided some detailed information on the species, 232 "Batrachuperus longdongensis" Liu \& Tian 1983 cannot be considered as the original spelling, 233 but is a junior homonym of the nomen nudum "Batrachuperus longdongensis" Liu \& Tian 1977. 234 Fei et al. (2006) evidently chose to adopt Batrachuperus londongensis as the original spelling in 235 a valid publication by Liu \& Tian (1978). Moreover, the species name Batrachuperus 236 londongensis is in prevailing usage in the current literature (e.g., Fei et al., 2006; Fei \& Ye, 237 2017; Fu \& Zeng, 2008; Fei, Ye \& Jiang, 2010, 2012; AmphibiaWeb, 2017; Frost, 2017; IUCN, 238 2016).

\section{External morphology}

241 Formalin-preserved specimens provide information on external morphology except for 242 coloration. Male adults of Batrachuperus londongensis have been measured at $190 \mathrm{~mm}-265 \mathrm{~mm}$ 243 in total length, and female adults at $183 \mathrm{~mm}-232 \mathrm{~mm}$ (Fei et al., 2006). Labial folds are well 244 developed, partly covering the lower lips; gular folds are arched posteriorly to demarcate the 
245 head from the trunk. Neotenes have one to four pairs of gill slits, whereas in postmetamorphic

246 individuals the gill slits are closed.

247 The presence or absence of eyelids and ring-shaped scleral cartilages in the eye are both 248 ontogenetically and ecologically significant characters. Movable eyelids are normally developed 249 at metamorphosis for adult life on land, but are often lacking in larvae and in those adults that are 250 obligate neotenes (Duellman \& Trueb, 1986). However, the ring-shaped scleral cartilage is 251 partly resorbed at metamorphosis in Hynobius and Onychodactylus (Okajima \& Tsuaki, 1921), 252 while the extent of resorption of the scleral cartilage in other hynobiids is largely unknown 253 (Rose, 2003). Our observations indicate that Batrachuperus londongensis has movable eyelids 254 but lacks scleral cartilages in both neotenes and postmetamorphic individuals. Although 255 developmental information is still unavailable, we infer that it is likely that scleral cartilages are 256 fully resorbed at metamorphosis or at sexual maturity as a normal developmental pattern as in 257 other hynobiids. Because the species is facultatively rather than obligately neotenic, possession 258 of movable eyelids may be indicative of their all-season aquatic life style being a secondary 259 adaptation.

260 The trunk region is more or less cylindrical, having 12-14 costal grooves on each side 261 along the trunk. A dorsal vertebral groove runs between the head and the base of the tail. The 262 tail is one-half or slightly longer than one-half of total length. The tail has a cylindrical base, but 263 becomes bilaterally compressed posteriorly, with evident dorsal and ventral fin folds extending 264 distally. The end of the tail displays a rounded outline in lateral view (Fei \& Ye, 2001). Toes in 265 the hind limb are reduced to four (Fei et al., 2006; Fei \& Ye, 2001), although occasional 266 developmental anomalies are found in some individuals (see below). Terminal digits are claw267 like, covered with a black cornified epidermal sheath. 
269 Dermal skull roof

270 The skull roof is flat, longer than wide as in other congeneric species (Fei et al., 2006). The

271 snout follows the contour of the maxillary arc: most specimens display a squarish outline, in

272 contrast to the rounded snout in other congeneric species (e.g., Batrachuperus pinchonii, $B$.

273 karlschmidti, B. tibetanus). The maximum width of the snout across the anterior borders of

274 orbits is much narrower than the maximum width of the skull at the cranio-mandibular joints,

275 thus giving a more or less trapezoidal outline of the skull roof in dorsal view (Fig. 2; Video S1).

276 This outline differs from that in $B$. pinchonii, which has a more rounded snout than $B$.

277 londongensis, and displays significant differences in the maximum width of the snout and at the

278 back of the skull (Fig. 2).

279 The paired premaxillae contact each other medially to close the anterior border of a large

280 anterodorsal fenestra (de Beer, 1937: cavum internasale) in the skull roof and an anteromedial

281 fenestra in the palate. The pars dentalis as the tooth-bearing part of the premaxilla forms the

282 anterior wall of the snout between the external nares, but its lateral extension articulates with the

283 maxilla to form the medial half of the ventral border of the narial opening. The anterior surface

284 of the premaxilla is penetrated by several small foramina. The pars dorsalis (alary process) of

285 the premaxilla ascends from the midlength of the pars dentalis, with the entire spine of the

286 process set in a groove on the anterodorsal surface of the nasal bone; therefore, the alary process

287 essentially contributes no part to the lateral border of the anterodorsal fenestra. A similar pattern

288 is seen in B. tibetanus (FMNH 5901), but not in other species of the genus.

289 The paired nasals are strongly widened to display a dimension almost twice the width of

290 the frontals, a plesiomorphic feature in urodeles as commonly seen in other hynobiids (Dunn, 
291 1923; Gao \& Shubin, 2012; Jia \& Gao, 2016a). In dorsal view, the nasal is a large plate,

292 irregular in shape, meeting its counter element along a midline suture. The nasal has an anterior

293 process, which is medially notched for the large anterodorsal fenestra and laterally notched for

294 the narial opening. A lateral process of the nasal is in limited contact with the lacrimal, because

295 a large part of the latter bone overlaps the prefrontal (Fig. 2). The dorsal surface of the nasal is

296 smooth, but is penetrated by several tiny foramina (foramen mediale nasi of Francis, 1934) that

297 serve as passage of ultimate twigs of the mesial branch of the ophthalmicus profundus nerve (CN

$298 \mathrm{~V}^{1}$ ) as seen in Salamandra (Francis, 1934). The nasal posteriorly overlaps the frontal

299 extensively, and laterally meets with the lacrimal and prefrontal. In dorsal view, the suture

300 between the nasal and frontal is located at the level of the anterior borders of the orbits.

301 The paired frontals are strongly elongated posteriorly, with a straight or slightly sigmoid

302 sutural contact along the midline. The paired elements occupy much of the interorbital area of

303 the skull roof, but form only a small part of the medial border of the orbit, with a large part of the

304 border furnished by the parietal. The frontal articulates with the nasal anteriorly and with the

305 prefrontal anterolaterally. Immediately behind the posterior process of the prefrontal, the lateral

306 border of the frontal curves downward to articulate with the orbitosphenoid; however, this

307 contact is limited to only the anterior one-third of the orbitosphenoid, with the posterior two-

308 thirds of the latter in contact with the parietal (Figs. 3,4). This short contact between the two

309 elements is also seen in B. karlschmidti, whereas in all other congeneric species the prefrontal

310 contacts over one-half of the dorsal margin of the orbitosphenoid (Figs. 3,4). Posteriorly, the

311 frontal overlaps the parietal extensively, with a strongly elongate posterior process extending to

312 the level of the medial (otic) process of the pterygoid. This strong posterior extension of the

313 frontal differs significantly from all other congeneric species, in which the frontal is 
314 proportionally shorter and terminates roughly at the midlevel of the orbit (e.g., FMNH 49380: $B$.

315 karlschmidti; FMNH 5901: B. tibetanus). Along the medial border of the orbit, the lateral

316 margin of the frontal curves downward to meet the orbitosphenoid and the anterolateral process

317 of the parietal.

318 The parietal is the largest element on the skull roof, but is extensively overlapped

319 anteriorly by the posterior extension of the frontal. The paired parietals meet at a straight or

320 slightly curved midline suture, and have parallel lateral borders forming most of the medial rim

321 of the orbit. The main part of the parietal table, however, is expanded bilaterally to form robust

322 lateral "boots" in articulation with the squamosals. The posterior part of the parietal table is

323 rugose dorsally, and posteriorly bears a bony ridge that curves anteriorly to house a deep fossa

324 (cervical epaxial fossa); both the bony ridge and fossa serve as insertion of the anterior epaxial

325 muscles (Carroll \& Holmes 1980; Duellman \& Trueb, 1986; Elwood \& Cundall, 1994). Slightly

326 anterior to the lateral boot of the parietal, the lateral surface of the parietal is pierced by a tiny

327 foramen that serves as the passage of the trochlear nerve (CN IV; Gaupp, 1911) as clearly seen in

328 several specimens (e.g., CIB 65I0013/14380, 14381, 14504, 14507, 14509). This foramen has

329 been identified in all other congeneric species that we have examined (B. karlschmidti, B.

330 taibaiensis, B. tibetanus, B. pinchonii, B. yenyuanensis) in this study and has also been reported

331 in several other salamanders (e.g., Francis, 1934: Salamandra; Wake, 2001: Dicamptodon;

332 AmphibiaTree, 2008: Ambystoma).

333 In both dorsal and lateral views, the parietal table sends an elongate anterolateral process

334 pinched between the frontal and orbitosphenoid (Figs. 3,4). Anteriorly, the pointed end of this

335 process terminates slightly anterior to the midlevel of the orbitosphenoid. At the posterior border

336 of the orbit, the parietal develops a short triangular process, which is ventrally directed in contact 
337 with a distinct pillar-like bone that in turn is ventrally in contact with the pterygoid. This small

338 pillar is identified as the perichondral ossification of the ascending process of the palatoquadrate,

339 and the presence of such a distinct bony element in Batrachuperus londongensis differs from all

340 other congeneric species but B. karlschmidti and B. taibaiensis (see below).

341 The prefrontal is a robust element, set at an oblique position in front of the large orbit.

342 The prefrontal meets the nasal and frontal medially; it underlies the lacrimal anteriorly and the

343 facial process of the maxilla laterally. The posterolateral margin of the prefrontal is curved to

344 form the anterodorsal rim of the orbit. The prefrontal has a well-developed posterior process that

345 extends far posterior to the nasal-frontal suture. A similar pattern is seen in Batrachuperus

346 tibetanus, but this process is much shorter in other congeneric species (B. karlschmidti, $B$.

347 taibaiensis, B. pinchonii, B. yenyuanensis). A prefrontal is normally present in most

348 salamanders, but is absent in proteids, sirenids, and some but not all plethodontids (Trueb, 1993;

349 Reilly \& Altig, 1996; Rose, 2003).

350 The lacrimal is a narrow and slightly elongate plate, with its main part overlapping the

351 prefrontal. The lacrimal is essentially rectangular, similar to that in B. tibetanus and B.

352 yenyuanensis, but differing from that in other congeneric species, in which the lacrimal is

353 triangular with a pointed anterior end (B. pinchonii and B. taibaiensis) or more or less "L"-

354 shaped with a short process bending posteromedially (B. karlschmidti). In B. londongensis, the

355 lacrimal has a limited contact medially with the nasal, but is in an extensive sutural articulation

356 laterally with the facial process of the maxilla. The canal for the nasolacrimal duct (ductus

357 nasolacrimalis) opens as a foramen posteriorly on the dorsal surface of the lacrimal (Fig. 2A),

358 with the anterior foramen opening on the anteroventral side of the lacrimal. As a common

359 feature seen in most of Batrachuperus species, the lacrimal extends anteriorly over the border of 
360 the external naris, but is posteriorly blocked by the prefrontal-maxillary contact from entering the

361 border of the orbit (Fig. 2). In other hynobiids, the lacrimal variably enters the naris only (e.g.,

362 Salamandrella), enters the orbit only (e.g., Pachyhynobius, Paradactylodon, some but not all

363 species in Hynobius), or enters both the naris and orbit (e.g., Liua, Onychodactylus,

364 Pseudohynobius, Ranodon, some species of Hynobius).

365 The maxilla is extremely short, but massively built, laterally covering the facial area of

366 the skull. The pars dorsalis of the maxilla is a robust process that widens between the narial

367 opening and the orbit. The process has an extensive sutural articulation with the lacrimal but a

368 limited contact with the prefrontal posterior to the lacrimal. The lateral wall of the maxilla is

369 slightly convex, and in some specimens (e.g., CIB 14485, 14509) is penetrated by a small

370 foramen anteriorly close to the narial rim. Ventral to the narial opening, the anteroventral

371 process of the maxilla articulates with the premaxilla to form one-half of the ventral border of the

372 naris. The posterior border of the pars dorsalis forms a part of the orbital rim, with the remaining

373 part furnished by the prefrontal. On the inner side of the pars dorsalis, a deep groove leads to a

374 small opening of the infraorbital canal, through which the superior alveolar branch of the

375 trigeminal nerve $\left(\mathrm{CN} \mathrm{V}^{2}\right)$ and its associated blood vessels pass as in other salamanders (Francis,

376 1934). In both neotenic and postmetamorphic individuals, the short posteroventral process of the

377 maxilla terminates at a level far anterior to the midlevel of the orbit. The short maxillary tooth

378 row contains no more than 18 teeth. The tooth row terminates close to the posterior extremity of

379 the maxilla.

380 The septomaxilla is a small bone exposed anteromedial to the narial border of the

381 maxilla. A septomaxilla is present in all hynobiids, and is also present in some other groups of

382 urodeles (Rose, 2003: ambystomatids, dicamptodontids, rhyacotritonids, and some but not all 
383 plethodontids). The absence of this element in several groups (sirenids, cryptobranchids,

384 amphiumids, and proteids) cannot be simply explained as a "paedomorphic loss" (contra

385 Duellman \& Trueb, 1986), because the absent condition is also seen in metamorphosed

386 salamandrids (Francis, 1934; Rose, 2003), let alone that the element is present in the Jurassic

387 neotenic salamanders Beiyanerpeton and Qinglongtriton (Gao \& Shubin, 2012; Jia \& Gao,

388 2016b). In this study, all known specimens of Batrachuperus londongensis consistently display

389 the septomaxilla in both neotenic and postmetamorphic adults. Ontogenetically, the

390 septomaxilla is ossified immediately before or during metamorphosis in Onychodactylus

391 (Vassilieva, Poyarkov \& Iizuka, 2013), Ranodon (Schmalhausen, 1968; Lebedkina, 2004),

392 Salamandrella (Schmalhausen, 1958; Lebedkina, 1964; Regel, 1970), and Hynobius (Vassilieva

393 et al., 2015).

394

\section{Suspensorium}

396 The squamosal is roughly T-shaped with its widened proximal end in articulation with the lateral

397 "boot" of the parietal and a transverse bar extending ventrolaterally over the quadrate (Fig. S1).

398 In dorsal view, the transverse bar is set at right angles in relation to the sagittal plane of the skull;

399 in occipital view, however, the transverse bar is set in an oblique position, sloping ventrolaterally

400 at a 45 degree angle towards the cranio-mandibular joint (Fig. S2). At the proximal end, a blunt

401 otic process projects anteriorly to articulate with the prootic, and a triangular process projects

402 posteriorly with its tip in contact with the opisthotic-occipital complex (Fig. 2). The squamosal

403 is slightly convex dorsally, but concave ventrally to embrace a large part of the quadrate.

404 The quadrate, as a principal element of the suspensorium, extends transversely beneath

405 the squamosal. In contrast to the squamosal, the quadrate has a widened lateral end and a medial 
406 process extending towards the stapes (columella). In dorsal view, the lateral end of the quadrate

407 is exposed beyond the distal end of the squamosal, where the quadrate thickens ventrally to form

408 a cartilage-lined saddle in articulation with the articular in the mandible. From the distal end, a

409 short and flat process overlaps the posterolateral process of the pterygoid. As revealed in CT

410 images of several specimens (e.g., CIB 65I0013/14380, 14381, 14507), a tiny quadrate foramen

411 pierces the base of the pterygoid process as passage of a branch of the posterior condylar artery

412 and vein as generally seen in other tetrapods (Olson, 1966). A quadrate foramen has been

413 identified in the Early Cretaceous hynobiid-like salamander Nuominerpeton (Jia \& Gao, 2016a),

414 whereas the occurrence of the foramen in extant hynobiids needs to be investigated thoroughly to

415 understand its phylogenetic significance. The ascending process of the quadrate extends beneath

416 the squamosal, and has a ligamentous connection with the stapes (see description of the stapes

417 below). Ossification of the quadrate occurs in all salamanders except sirenids (Rose, 2003).

418 Ontogenetic ossification of the quadrate in different hynobiid species can be variably before

419 (Suzuki, 1932; Lebedkina, 2004; Jia \& Gao, 2016a), during (Lebedkina, 1964), or immediately

420 after metamorphosis (Vassilieva et al., 2015).

421 The pterygoid is triradiate in ventral view (Fig. 4; Fig. S3). The anterolateral (palatal)

422 process is elongated, extending to a point slightly anterior to the midlevel of the orbit; thus, the

423 ligamentous connection with the maxilla is extremely short. As a common pattern in other

424 salamanders, all hynobiids have a ligamentous connection between the maxilla and pterygoid,

425 with the exception of Pachyhynobius, in which a bony contact between the two elements is

426 established (Fei et al., 2006). In B. londongensis, the ventral surface of the anterolateral process

427 is smooth, but the dorsal surface is grooved to receive a slender rod of cartilage (processus 
428 pterygoideus of the palatoquadrate), which extends along the entire length of the anterolateral 429 process of the pterygoid.

430 The posterolateral (quadrate) process of the pterygoid is slightly shorter than the

431 anterolateral process. A large part of the former process underlays the quadrate to reinforce the

432 cranio-mandibular joint. In addition to serving as a part of the suspensorium, the pterygoid also

433 serves as insertion of adductor muscles, including the pterygoideus head of the adductor

434 mandibulae internus (Carroll \& Holmes, 1980). The medial (otic) process of the pterygoid is

435 short, but turns dorsally to meet a small pillar (ossified ascending process of the palatoquadrate);

436 thus, the process has no bony contact with the parasphenoid. Lack of a synostotic contact

437 between the pterygoid and parasphenoid is a common pattern in all other Batrachuperus species.

438 As mentioned above, it is of special interest to note the presence of a short pillar

439 upholding the parietal immediately anterior to the prootic (Figs. 2,3). To our knowledge, this

440 short pillar represents the perichondral ossification of the ascending process of the

441 palatoquadrate (Trueb, 1993: metapterygoid; Rose, 2003: epipterygoid). The short pillar is set in

442 a vertical or slightly oblique orientation, dorsally in articulation with a downward process of the

443 parietal and ventrally with the upward medial process of the pterygoid. In other salamanders, the

444 ascending process of the palatoquadrate normally remains unossified, whereas a "certain amount

445 of perichondral ossification" of the process has been documented in Salamandra (Francis, 1943:

446 26) as part of the suspensorium.

447 In this study, all of the adult specimens of Batrachuperus londongensis that we have

448 examined consistently show the presence of this pillar in the same position, and the same contact

449 patterns of the bone with the parietal and pterygoid can be seen in both dorsal and lateral views

450 (Figs. 2,3). CIB 14500 is a postmetamorphic juvenile, which shows that this pillar is not yet 
451 ossified, as the individual also lacks ossification of the articular in the lower jaw (see below).

452 However, B. karlschmidti (FMNH 49380) and B. taibaiensis (CIB 20040235) are the two

453 congeneric species that show the presence of this bone and the same articulation patterns as in $B$.

454 londongensis. In other hynobiids, ossification of the pillar as part of the suspensorium is also

455 seen in Paradactylodon mustersi (FMNH 211936) and Pseudohynobius flavomaculatus (CIB

456 79I0107/17344). Whether this ossification represents a plesiomorphic feature with a

457 homologous origin or a derived state independently acquired needs to be investigated in a

458 phylogenetic analysis.

459

460 Palate and braincase

461 Formation of the palate involves the partes palatina of the premaxillae and maxillae, the vomers,

462 and the anterior portion of the parasphenoid. The partes palatina of the premaxillae are the

463 lingual shelves of the premaxillae that meet at the midline to close the anterior border of the

464 large palatal fenestra (Fig. 4; Fig. S3). The fenestra (Schmalhausen, 1968: intervomerine cleft;

465 Trueb, 1993: anteromedial fenestra) is the palatal opening for the intermaxillary gland

466 (Schmalhausen, 1968). Laterally, the pars palatina of the maxilla contacts the vomer to complete

467 the lateral rim of the palate.

468 In some neotenic individuals (e.g., CIB 14381, 14482), the ossified palatine is retained as

469 a discrete element either in articulation with or free from the anterior process of the pterygoid on

470 both sides of the palate (Figs. 2-4). In these specimens, the toothless palatine occurs as a small

471 plate or a slender bar. The palatine is entirely resorbed in all other hynobiids in the adult stage as

472 is commonly seen in other salamanders except sirenids (Worthington \& Wake, 1971; Smirnov \&

473 Vassilieva, 2002; Rose, 2003); therefore, the retention of this element as an ossification in some 
474 but not all specimens in Batrachuperus londongensis can be interpreted as an ontogenetic

475 feature. This interpretation is supported by the hynobiid-like fossil salamander Nuominerpeton

476 aquilonaris of Early Cretaceous age from China, which displays normal resorption of the

477 palatine at metamorphosis (Jia \& Gao, 2016a). Furthermore, none of the specimens of $B$.

478 londongensis that we examined have shown a separate palatine at a postmetamorphic stage, and

479 large neotenic individuals (e.g., CIB 65I0013/14380, 14484, 14485) also lack this element.

480 Because those specimens having a discrete palatine are apparently adult individuals, ontogenetic

481 resorption of the element in these individuals seems to be delayed until after sexual maturity.

482 The vomer is a large plate, irregular in shape, slightly longer than wide. The two vomers

483 are widely separated from one another, thus allowing the parasphenoid to enter the posterior

484 border of the anteromedial fenestra (Fig. 4; Fig. S3). This pattern is consistently observed in all

485 specimens, and thus is recognized in this study as a unique feature different from all other

486 species in Batrachuperus and other hynobiids as well. Jömann, Clemen \& Greven (2005: fig.

487 33) figured Ranodon sibiricus at the adult stage as showing no midline contact of the vomers, but

488 this was probably based on juvenile or subadult specimens (Jömann, Clemen \& Greven, 2005:

489 table 1: $\mathrm{TL}=<150 \mathrm{~mm}$ ) as the nasals are widely separated (Jömann, Clemen \& Greven, 2005:

490 fig. 32) in contrast to the condition in fully grown adults (maximum $\mathrm{TL}=250 \mathrm{~mm}$ ) as figured in

491 Fei et al. (2006: fig. 67). In B. londongensis, the medial border of the vomer is slightly concave,

492 forming the entire lateral margin of the anteromedial fenestra (Fig. 4; Fig. S3). Posterolaterally,

493 the vomerine plate is notched for the choana, with a small triangular process projecting towards

494 the orbit to embrace the notched choana. However, a retrochoanal (postchoanal) process is

495 absent, as a laterally directed process to block the posterior border of the choana is clearly 
496 lacking. Another projection, medially attached to the parasphenoid, represents the posterior 497 process of the vomer (Fig. 4; Fig. S3).

498 A large part of the ventral surface of the vomer is smooth, except for a small tooth499 bearing area medial to the choana. The vomerine teeth are four to eight in number, arranged in a 500 linear fashion to form a straight row. The two vomerine tooth rows are widely separate but 501 slightly oblique, convergent anteriorly and divergent posteriorly. This arrangement differs from 502 most other congeneric species: in them the vomerine tooth row is more or less arched and 503 parallel to the maxillary tooth row. Close to the premaxilla-vomer suture, the vomer is 504 penetrated by two to three small foramina observed in several specimens (CIB 65I0013/14380, 505 14381, 14504, 14509; Fig. S4), probably for passage of the ramus ventralis of the trigeminal 506 nerve $\left(\mathrm{CN} \mathrm{V}^{1}\right)$ and the ramus palatinus of the facial nerve (CN VII) to supply the mucous 507 membranes of the mouth, as in other salamanders (Francis, 1934: Salamandra salamandra; 508 Cloete, 1961: Rhyacotriton olympicus).

509 The parasphenoid is a dermal bone that forms a large median plate, roughly rectangular 510 in outline, with straight lateral borders parallel to one another. The anterior process of the 511 parasphenoid contributes to part of the palate and closes the posterior border of the anteromedial 512 fenestra (Fig. 4; Fig. S3). The anterolateral part of the parasphenoid bears a flat facet, where part 513 of the vomer posterolateral to the anteromedial fenestra is attached. The lateral edge of the 514 parasphenoid curves dorsally, with a narrow groove in articulation with the ventral edge of the 515 orbitosphenoid. Posteriorly, the basal plate of the parasphenoid is widened to form the lateral ala 516 that floors the otic capsule. Close to the anterolateral border of the basal plate, a pair of internal 517 carotid foramina penetrates the parasphenoid as passage of the internal carotid arteries. As 518 observed in several specimens (CIB 65I0013/14380, 14381, 14482, 14504, 14507, 14509), more 
519 than one foramen may occur on either side of the parasphenoid, possibly indicating minor

520 branches of the artery. The lateral ala has no bony contact with the otic process of the pterygoid,

521 but has an articulation with the prootic (Fig. 4; Fig. S3). The posterior end of the parasphenoid

522 forms a blunt posteromedian process, which furnishes the ventral rim of the foramen magnum.

523 The orbitosphenoid (sphenethmoid) as an endochondral bone is a rectangular plate that

524 covers a large part of the anterolateral wall of the braincase. The bony plate dorsally articulates

525 with the frontal and parietal, but in some specimens (e.g., CIB 65I0013/14380) it also articulates

526 with the prefrontal (Figs. 3,4; Fig. S1). The entire ventral edge of the orbitosphenoid meets the

527 parasphenoid. The anterior edge of the orbitosphenoid is vertical, forming a straight border of

528 the orbitonasal fenestra; the posterior border, however, is deeply notched for the optic foramen,

529 carrying the optic nerve and its associated vessels (Francis, 1934; Fox, 1959). There is no

530 foramen in the orbitosphenoid as passage of the oculomotor nerve (CN III); instead, this nerve

531 passes through the optic-oculomotor commissure, which is covered by cartilaginous tissues

532 posterior to the orbitosphenoid. This pattern of cranial nerves exiting through the anterolateral

533 wall of the braincase has been recognized as a diagnostic feature of the Hynobiidae (Jia \& Gao,

534 2016a), differing from the sister group Cryptobranchidae, in which the optic foramen is fully

535 surrounded by the bony rim of the orbitosphenoid.

536 A separate operculum is absent in B. londongensis, as is common in most of other

537 hynobiids but Hynobius, in which the operculum is present as a separate element (Monath, 1965;

538 Rose, 2003). An operculum is figured as present in Liua shihi (Zhang, 1985) and Ranodon

539 sibiricus (Jömann, Clemen, \& Greven, 2005: fig. 34); however, the element that is labeled in

540 both cases seems to be the stapes as it has a rounded footplate fused with the stylus. 
541 No operculum, bony or cartilaginous, is identified in any of the specimens. The stapes

542 (columella) has a massive and disc-like footplate covering the foramen ovalis. The stylus is

543 extremely short, fused with the footplate proximally but with a small facet at its obtuse distal

544 end, where the ligamentum squamoso-columellare attaches; the ligament connects the stapes

545 with the quadrate and squamosal (Kingsbury \& Reed, 1909). A stapedial foramen is

546 unexpectedly present on both sides in two specimens (CIB 65I0013/14380, 14381; both neotenic

547 individuals), penetrating the stylus horizontally (Fig. S2). In two other specimens (CIB 14507,

548 14509; both postmetamorphic individuals), a foramen penetrates left and right stapes, as well.

549 However, none of the other specimens, neotenic or postmetamorphic, show the presence of the

550 foramen. Therefore, the stapedial artery and/or the hyomandibular trunk of the facial nerve $(\mathrm{CN}$

551 VII) in this species can variably pass through the stapedial foramen or below the short stylus. A

552 similar condition is known for Ranodon sibiricus: Schmalhausen (1968) described both present

553 and absent conditions of the stapedial foramen in specimens observed by him. Although Trueb

554 \& Cloutier (1991) interpreted the absence of a stapedial foramen as a batrachian synapomorphy,

555 its presence in some salamanders is more likely to be a plesiomorphic feature for Urodela

556 because it also occurs in the stem caudate Karaurus (Ivachnenko, 1978; Estes, 1981).

557 Furthermore, the foramen is found in the Late Jurassic salamandroids Beiyanerpeton and

558 Qinglongtriton from China (Jia \& Gao, 2016b). The discovery of the presence of this foramen in

559 some but not all postmetamorphic individuals in Batrachuperus londongensis casts more doubt

560 on our understanding of the evolution of this character.

561 The prootic is irregular in shape, covering the lateral wall of the anterior portion of the

562 otic capsule. The element dorsally articulates with the parietal, but a small part of its dorsal rim

563 underlays the squamosal as well. Ventrally, the prootic articulates with the lateral ala of the 
564 parasphenoid. In lateral view, the alary process (optic process) of the prootic is a small flap

565 directed anterodorsally; the inferior process (basal process) of the prootic is more or less

566 triangular, with its ventral edge in articulation with the parasphenoid (Fig. 3; Fig. S1). A large

567 foramen faciale penetrates the lateral surface of the prootic as passage of the facial nerve (CN 568 VII).

569 The opisthotic and exoccipital are fully fused to form an opisthotic-exoccipital complex 570 covering the posterior wall of the braincase. The complex dorsally articulates with the parietal

571 and ventrally with the parasphenoid; in dorsal view, it is swollen posterolaterally as the housing

572 of the auditory capsule. The opisthotic portion of the complex borders the fenestra ovalis

573 anteriorly, whereas its exoccipital part borders the foramen magnum posteromedially and bears

574 the occipital condyle posteriorly in articulation with the cotyle of the atlas (Fig. S2). At the base

575 of the occipital condyle, the complex in penetrated by the foramen post-oticum (Fig. S2) through

576 which the combined glossopharyngeus-vagus nerves passes (CN IX + X; Francis, 1934). In all

577 hynobiids the opisthotic-exoccipital complex is fused and the prootic free (Carroll \& Holmes,

578 1980; contra Trueb, 1993: three separate elements), except for Onychodactylus, in which the

579 prootic is fused to the opisthotic-exoccipital complex (Smirnov \& Vassilieva, 2002; Vassilieva,

580 Poyarkov \& Iizuka, 2013). In occipital view, the foramen magnum is roughly triangular in

581 outline. The dorsal rim of the foramen has a median gap where the cartilaginous tectum

582 synoticum attaches below the parietals. The ventral border of the foramen magnum is largely

583 formed by the posteromedian process of the parasphenoid.

584

585 Mandible 
586 As in all cryptobranchoids (hynobiids and cryptobranchids), the lower jaw of Batrachuperus

587 londongensis consists of the dentary, prearticular, angular, and articular. In addition, a small

588 posterior mental process seen in all specimens at the symphysis gives a clear indication of the co-

589 ossification of a mentomeckelian element with the dentary (Fig. 5; Fig. S3).

590 The dentary is the largest bone of the mandible, covering most of its lateral and ventral

591 aspect. The lateral surface of the dentary is smooth, slightly swollen along the lower border but

592 weakly concave along the tooth row. A large foramen is often located at a position slightly

593 posterior to the midlevel of the dentary tooth row (Fig. 5). This foramen marks the passageway

594 of the mandibularis externus nerve $\left(\mathrm{CN} \mathrm{V}_{3}\right)$, innervating both the skin and the muscle (M.

595 intermandibularis) between the two rami of the lower jaw (Francis, 1934). Posteriorly, the

596 dentary terminates at a robust process below the cranio-mandibular joint.

597 Posteroventral to the dentary, the angular bone is exposed in medial, ventral, and lateral

598 views. As observed in both lateral and ventral views, the angular is slightly thickened

599 posteriorly but narrows anteriorly, where it is wedged between the prearticular and the dentary

600 (Fig. 5; Fig. S3). The pointed anterior process terminates at a level slightly posterior to the

601 anterior extremity of the anterolateral process of the pterygoid, and the thickened posterior end

602 forms the posteroventral extremity of the mandible. In medial view, a small angular foramen

603 opens anteroventrally at the angular-prearticular suture, close to the anterior end of the angular

604 and below the coronoid process of the prearticular.

605 The prearticular is a large element covering most of the medial aspect of the jaw.

606 Anteriorly, the bone terminates at a point close to the mandibular symphysis. Posterodorsally,

607 the prearticular rises to form a large ascending process (coronoid process) that serves as insertion

608 of the adductor mandibulae internus. The process slopes downward posteriorly and continues as 
609 a ridge that attaches to the medial side of the articular at the glenoid fossa. Below and

610 posteroventral to the coronoid process, the prearticular is penetrated by one or two foramina

611 (inferior dental foramina) as passage of the inferior alveolar ramus of the facial nerve (CN VII)

612 and the alveolar artery (Francis, 1934). There is often a third foramen that serves as passage of

613 the same nerve and vessel opening more anteroventrally at the tip of the angular bone.

614 The articular is well ossified in adults as in other extant species and fossil relatives of

615 hynobiids but is absent in cryptobranchids (Reese, 1906; Rose, 2003; Jia \& Gao, 2016a). In

616 comparison to the angular, the articular is slightly shorter but more stoutly built. In dorsal view,

617 the anterior process of the articular extends between the prearticular and dentary, terminating at

618 an obtuse tip medial to the coronoid process of the prearticular (Fig. 5). The slightly expanded

619 posterior part of the articular is in articulation with the quadrate. As revealed from CT-scanned

620 images, a tube-like canal runs horizontally through the articular as the passage of the ramus

621 hyomandibularis of the facial nerve (CN VII); whether this pattern occurs in other congeneric

622 species and other hynobiids needs to be thoroughly investigated. Ontogenetically, the articular

623 ossifies slightly later than the septomaxilla after metamorphosis (Smirnov \& Vassilieva, 2002;

624 Rose, 2003; Lebedkina, 2004; Vassilieva, Poyarkov \& Iizuka, 2013; Vassilieva et al., 2015);

625 thus, presence of a bony articular is a clear indication of maturity in fossil and extant hynobiids

626 (Jia \& Gao, 2016a). In this study, CIB 14500 is a postmetamorphic juvenile (TL=110 mm;

$627 \mathrm{SPL}=60.24 \mathrm{~mm}$ ), which displays a typical postmetamorphic pattern of the hyobranchium but

628 shows no ossification of the articular. Once again, comparison of this with other specimens

629 indicates that the articular is ossified after metamorphosis in Batrachuperus londongensis. This

630 ossification sequence of the articular is similar with some other hynobiids, for example,

631 Onychodactylus japonicus (Smirnov \& Vassilieva, 2002) and Hynobius formosanus (Vassilieva 
632 et al., 2015), but differs from that in Ambystoma, in which the element is ossified during

633 metamorphosis (Reilly, 1987).

634

\section{Dentition}

636 Tooth-bearing elements in Batrachuperus londongensis include the premaxilla, maxilla, vomer,

637 and dentary. The premaxilla carries seven to nine teeth; the tooth rows on both sides are slightly

638 curved to form a broad arc, corresponding to the blunt snout. The maxilla carries 16-18 teeth,

639 with the tooth row terminating at the posterior extremity of the maxilla.

640 As described above, each vomer bears a single tooth row containing four to eight teeth.

641 The tooth row is essentially straight, but arranged obliquely medial to the choana with the two

642 tooth rows slightly converging anteriorly. The tooth rows are set far apart from one another,

643 corresponding to the separation of the vomers. Other palatal elements, including the

644 parasphenoid and pterygoid, are entirely edentulous.

645 The dentary tooth row is slightly longer than that of the maxilla, terminating posteriorly

646 at a point slightly anterior to the coronoid process of the prearticular. There are $20-25$ teeth on

647 the dentary. All marginal teeth and vomerine teeth are pedicellate, with the basal pedicel and

648 crown separated by a poorly mineralized dividing zone. Tooth crowns are bicuspid as

649 commonly seen in most salamanders.

650

651 Hyobranchial apparatus

652 The hyobranchial apparatus in Batrachuperus londongensis has been shown to have two

653 different patterns related to life-history differences (Fei et al., 2006: fig. 69). The neotenic 
654 pattern retains some of the larval branchial arches, and thus displays more complex structures

655 than in the postmetamorphic pattern (Fig. 6; Fig. S3).

656 Cartilaginous elements cannot be observed in our CT-scanned images, but can be

657 detected in cleared and stained specimens (Fig. 6). A cornua is present as a partly mineralized

658 median plate in the postmetamorphic pattern, whereas it is absent in neotenes (Fig. 6A,B). In

659 both neotenic and postmetamorphic individuals, the paired radial loops stemming from

660 basibranchial I (anterior copula) extend anteriorly, then curve laterally in continuation with the

661 ceratohyal. Therefore, the paired radial loops do not cross one another, in contrast to

662 Batrachuperus pinchonii and some other hynobiids (Onychodactylus, Hynobius,

663 Pseudohynobius, Pachyhynobius), in which a figure 8-shaped pattern is formed by a complex

664 crossing of the radial loops (Larson et al., 1996; Rose, 2003; Xiong et al., 2013b).

665 Basibranchial I (anterior copula) remains cartilaginous in both neotenic and

666 postmetamorphic individuals as in all other hynobiids except Onychodactylus, in which the

667 element is partly ossified as a short stub (Fukuda, 1930; Smirnov \& Vassilieva, 2002; Xiong et

668 al., 2013b). Presence or absence of basibranchial II (posterior copula, os thyroideum of Rose,

669 2003) was previously unknown for Batrachuperus londongensis. Observation of multiple

670 specimens in this study reveals that basibranchial II is well ossified, displaying two different

671 patterns that may reflect developmental differences (see below): most specimens have an

672 anteriorly directed rod jointed with a transverse bar to form a simple inverted "T"-shaped

673 structure (Fig. 6B; Fig. S3A-E); other specimens have a long anterior rod connected with a

674 complex base, which displays multiple short branches directed posteriorly, termed here the

675 "fork"-shaped pattern (Fig. S3F). None of the specimens on which this study is based shows an

676 anchor-shaped basibranchial II, a configuration that has been recognized as a plesiomorphic 
677 condition for urodeles (Jia \& Gao, 2016b). The anchor-shaped basibranchial II occurs in the 678 stem caudate Karaurus (Ivachnenko, 1978; Estes, 1981), basal cryptobranchoid Chunerpeton 679 (Gao \& Shubin, 2003), and basal salamandroid Beiyanerpeton (Gao \& Shubin, 2012). The 680 plesiomorphic pattern is not seen in any extant hynobiids (see Xiong et al., 2013b), but occurs in 681 the basal hynobiid Nuominerpeton (Jia \& Gao, 2016a). Hypobranchial I and ceratobranchial I remain separate in Batrachuperus londongensis, in 683 contrast to the fusion in B. pinchonii, B. tibetanus (Fei et al., 2006), and several other hynobiids 684 (Ranodon, Hynobius, Pseudohynobius, Salamandrella, Liua) (Fei et al., 2006; Zhang et al., 2009; 685 Xiong et al., 2013b). Hypobranchial I in most specimens remain cartilaginous, but ossification 686 of the element occurs in large neotenes (CIB 65I0013/14380, 14381). CIB 14504 is the only postmetamorphic individual that has it as a bony rod (Fig. 6B; Fig. S3B). Ceratobranchial I is 688 increasingly ossified ontogenetically in neotenes (CIB 65I0013/14380, 14381, 14482, 14484, $14485,14499)$, but it remains cartilaginous in all postmetamorphic individuals. Whether bony or 690 cartilaginous, the distal end of ceratobranchial I is slightly hooked, bearing a small process that curves posterodorsally (Figs. 6,7; Video S1).

692 Hypobranchial II and ceratobranchial II are both ossified as separate elements as in all 693 other hynobiids (Fei et al., 2006; Xiong et al., 2013b). The former element is basically rod-like, slightly thicker posteriorly than anteriorly; the shaft can be relatively straight or slight curved 695 laterally. Ceratobranchial II is much longer than hypobranchial II, and often displays an expanded distal end, which is bilaterally compressed into a distal plate. This is especially the case in large neotenes, including the holotype. At midlength in the long rod, a prominent process 698 projects dorsomedially where the subarcualis rectus II attaches as in Amphiuma (Erdman \& 699 Cundall, 1984). Ceratobranchials III and IV are normally absent in postmetamorphic individuals 
700 (but see below), whereas they are present as bony elements in neotenes (Figs. 6,7). CIB 14487 is

701 a postmetamorphic young adult $(\mathrm{TL}=164 \mathrm{~mm}$; $\mathrm{SPL}=89.27 \mathrm{~mm})$; its adulthood is indicated by

702 ossification of the articular in the lower jaw, but it displays remnant ceratobranchial III in the

703 process of being resorbed (Fig. S3E).

704 The ceratohyal in both postmetamorphic and neotenic individuals is distally ossified, with

705 large adults showing more extensive ossification than smaller ones. In the holotype (CIB

706 65I0013/14380), the largest specimen known for the species $(\mathrm{TL}=265 \mathrm{~mm})$ and a neotene, over

$70760 \%$ of the ceratohyal is ossified as a robust element, leaving only the anterior one-third

708 cartilaginous (Fig. 7B; Fig. S3A). The ossified part of element has a prominent ridge

709 posterodorsally bearing a ligamentous connection with the suspensorium (Trueb, 1993; Rose,

710 2003). Partial ossification of the ceratohyal is also seen in all other species of Batrachuperus: $B$.

711 pinchonii (Zhang et al., 2009: fig. 24); B. tibetanus (FMNH 5901); B. yenyuanensis (FMNH

712 49371); B. karlschmidti (FMNH 49380); B. taibaiensis (CIB 20040235). Among other

713 hynobiids, partial ossification of the ceratohyal distally occurs in Pachyhynobius

714 shangchengensis, Liua shihi, and Ranodon sibiricus (Zhang, 1985; Fei et al., 2006).

715

\section{Axial skeleton}

717 As consistently observed from all B. londongensis specimens studied here, the vertebral column

718 consists of 18 presacral vertebrae, including the atlas, plus a single sacral, three to four

719 caudosacrals, and 29-30 caudal vertebrae (Fig. 7; Video S2). The number of the presacral

720 vertebrae is different from the type species, Batrachuperus pinchonii (Zhang et al., 2009; Xiong

721 et al., 2013a; but see Litvinchuk \& Borkin, 2003: 16-17), as well as several other congeneric

722 species (B. tibetanus, B. karlschmidti, and B. yenyuanensis), which have 17 presacrals by our 
723 own observation. Among other hynobiid species, the number of presacral vertebrae ranges from

72415 in Ranodon sibiricus to 22 in Onychodactylus fischeri (Litvinchuk \& Borkin, 2003).

725 In both dorsal and ventral views, the atlas is widened anteriorly, where it bears a pair of

726 cotyles that receive the occipital condyles. Anteroventral to the cotyles is the odontoid process

727 (tuberculum interglenoideum), which bilaterally articulates with the exoccipitals at the rim of the

728 foramen magnum. Posterior to the odontoid process, the ventral surface of the atlas is penetrated

729 by a pair of foramina through which the first pair of spinal nerves pass. The atlas has no

730 transverse process or free ribs.

731 In all trunk vertebrae, the centrum is more or less cylindrical and is deeply amphicoelous.

732 There is no significant change in length of the centrum along the trunk series, and all trunk

733 vertebrae bilaterally bear transverse processes that are directed posterolaterally. A shallow

734 groove is visible on the posterior surface of the transverse process, indicative of fusion of the

735 dorsal diapophysis with the ventral parapophysis. Because of this fusion, the articulation facets

736 of the diapophysis and parapophysis are confluent to receive the unicapitate ribs.

737 All presacral vertebrae except the atlas articulate with free ribs. The ribs associated with

738 the first three trunk vertebrae are more robust than the remaining ribs, having the distal end

739 expanded where the M. thoracic-scapularis attaches (Francis, 1934). In addition, the first pair of

740 ribs often bears a short uncinate process distally, so that the ribs are distally forked (e.g., CIB

741 14482, 14484, 14485, 14487; Fig. S3; Video S2). The ribs are similar in length for most of the

742 trunk series, but the posterior four to five pairs are abruptly shortened, with the last pair being a

743 remnant stub that is even shorter than the transverse process of the associated vertebra. All trunk

744 ribs are essentially single headed, although a shallow groove can be recognized posteriorly on

745 the rib head as indication of fusion of the dorsal tuberculum with the ventral capitulum. 
746 Possession of unicapitate ribs is a diagnostic feature of the suborder Cryptobranchoidea (Dunn,

747 1923; Duellman \& Trueb, 1986; Gao \& Shubin, 2012; Jia \& Gao, 2016a).

748 The single sacral vertebra is roughly the same size as the presacrals, but the transverse

749 process of the sacral is obviously more robust than that of the trunk vertebrae. The sacral rib is

750 elongated to at least twice the length of the transverse process, and curves ventrally to bear a

751 ligamentous connection with the ilium.

752 The three rib-bearing vertebrae following the sacral are identified as caudosacrals, with

753 the first haemal arch bearer marking the position of the anus. CIB 14485 is the only examined

754 specimen that displays four caudosacrals. These caudosacrals are roughly the same size as the

755 sacral vertebra, but ribs associated with them are greatly reduced, being slightly shorter than the

756 corresponding transverse process. Possession of three or more caudosacrals seems to be

757 plesiomorphic in urodeles (Gao \& Shubin, 2001, 2012; Jia \& Gao, 2016b). In fully grown

758 adults, 28-30 vertebrae follow the caudosacral series (Fig. 7; Video S2). The caudal vertebrae

759 normally have no free ribs, but occasionally remnant ribs occur in the first caudal in some

760 specimens (CIB 14484, 14487). All caudal vertebrae, except the posterior-most two or three,

761 ventrally bear a haemal arch, through which the haemal vessels pass.

762

763 Appendicular skeleton

764 Pectoral girdle and forelimbs

765 A large part of the pectoral girdle remains cartilaginous, with only the scapulocoracoid co-

766 ossified as a single unit. A co-ossified scapulocoracoid occurs in all other salamanders but

767 sirenids, in which the scapula and coracoid remain separate (Noble, 1931). The scapulocoracoid

768 in Batrachuperus londongensis has an extremely short scapular blade as in other species of the 
769 genus, but the dorsal border of the blade bears a distinct process projecting posterodorsally (Fig.

770 8; Video S2), a feature not seen in other Batrachuperus species. Because this process is

771 consistently prominent in all specimens under study (Table 1), it is recognized here as a

772 diagnostic feature of the species. Judging from its posterodorsal position, it unlikely served as

773 insertion of the opercular muscle, but more likely as ligamentous insertion of a levator muscle of

774 the shoulder; whereas it is the levator scapulae inferior or the intertransversaricus capitis inferior

775 needs to be further investigated (see Gaupp, 1898; Kingsbury \& Reed, 1909; Goodrich, 1930;

776 Monath, 1965). Anterior to this process, the dorsal border of the scapular blade displays an

777 elliptical depression that articulates the suprascapular cartilage.

778 In the ventral part of the pectoral girdle, the procoracoid and coracoid are fully co-

779 ossified to form a large plate, which is expanded anteroposteriorly and curved ventromedially.

780 In lateral view, the anterior border of the coracoid plate is straight, but the ventral border is

781 rounded. Both the anterior and ventral borders are grooved to receive the cartilaginous part of

782 the procoracoid and coracoid, respectively. Close to the posterodorsal border of the coracoid

783 plate is a large glenoid fossa, which receives the head of the humerus. The glenoid fossa is

784 roughly circular, but its anteroventral rim is deeply notched where the crista ventralis of the

785 humerus fits (see below). Anteroventral to the glenoid fossa, a small supracoracoid foramen

786 (occasionally two openings) penetrates the coracoid plate as passage of the supracoracoideus

787 nerve (from the second and third spinal nerves) and its associated vessels (Francis, 1934). In

788 addition, it is interesting to note that some specimens (e.g., CIB 65I0013/14380, 14504) display

789 partial ossification of what otherwise is the cartilaginous part of the procoracoid and coracoid

790 (Fig. 8; Video S2). Because extra ossification of these cartilaginous parts occurs only in very 
791 large specimens of both postmetamorphic and neotenic individuals, it can be viewed as a

792 developmental feature but one that cannot be tied with neoteny or metamorphosis.

793 The humerus is significantly longer than the ulna or radius. Proximally on its extensor

794 aspect, the crista dorsalis (dorsal crest) bears a prominent triangular or even knob-like projection,

795 onto which the M. subscapularis inserts (Francis, 1934). Proximally on the flexor aspect, the

796 crista ventralis (ventral crest) is a large triangular process, projecting anteroventrally where the

797 M. pectoralis and M. supra-coracoideus attach (Francis, 1934); the ventral crest merges with the

798 head of the humerus (or a facet in some specimens; see below). When the forelimb swings

799 forward, the crista ventralis fits into the notch of the anteroventral rim of the glenoid fossa as

800 mentioned above. Immediately ventral to the humeral head, a small but deep ventral depression

801 marks the insertion of the flexor muscle M. humero-artibrachialis (Francis, 1934). In young

802 adult specimens (e.g., CIB 14484, 14485, 14487), the humerus head is a cartilaginous cap, and

803 thus, CT-scanned images show a shallow facet; in fully grown adults (e.g., CIB 65I0013/14380,

$80414381,14482,14504,14509)$, the humeral head is ossified into a large spherical condyle (Figs.

805 7, 8G-L). Among the latter, no postmetamorphic specimens show a cartilaginous cap, whereas

806 only relatively small neotenic individuals show a cartilaginous condyle. Distally, the olecranon

807 fossa on the extensor side of the humerus is extremely shallow, barely recognizable, but the fossa

808 cubitalis ventralis on the flexor side is a deep triangular depression, which receives the radius

809 when the forearm is flexed. In relatively small neotenes, the radial and ulnar condyles are

810 unossified, with the distal end of the humerus bearing two facets, where the cartilaginous ulnar

811 and radial condyles attach.

812 In the forearm, both the ulna and radius are straight, subequal in length and

813 approximately two-thirds the length of the humerus. The proximal end of the ulna is more 
814 expanded than its distal end, and conversely the radius is a more expanded distally.

815 Posterolaterally, the ulna bears a bony crest that serves as insertion of the extensor of the forearm

816 (M. extensor antibrachii ulnaris). The radius is distally in articulation with the radiale and

817 intermedium. Close to its proximal end, the radius posterodorsally bears a prominent process,

818 which serves as ligamentous insertion of the M. humero-antibrachialis, the main flexor muscle of

819 the elbow (Francis, 1934). As described above for the humerus, in those specimens having a

820 well-ossified humeral condyle, the epiphyses of the radius and ulna are also ossified, leaving no

821 space for a cartilaginous cap.

822 Maximum ossification of the mesopodium in the forelimb displays a total of seven

823 elements as observed in several specimens including the holotype (CIB 65I0013/14380, 14381,

824 14482, 14505, 14507, 14509), whereas other specimens (CIB 14484, 14485, 14487) have six

825 ossified elements, with preaxial elements (radiale + element y) remaining cartilaginous (Fig.

826 9B,C). In those specimens showing maximum ossification, the intermedium proximally wedges

827 between the ulna and radius, and distally wedges between the centrale and ulnare (Fig. 9A,B,D).

828 The large radiale may represent a fusion of the radiale with element $y$, because no space for a

829 possible element $\mathrm{y}$ is present in these specimens. The single large centrale is in direct contact

830 with the radius, thus separating the radiale from contact with the intermedium. This pattern is

831 also seen in all other congeneric species, including Batrachuperus yenyuanensis (FMNH 49371),

832 which is the only known species of the genus in which two centralia occur. In B. londongensis,

833 the radiale is slightly smaller than the centrale, and articulates with the radius proximally, the

834 basale commune distally, and the centrale laterally. The basale commune is a large element,

835 roughly triangular in shape. It is in articulation with the centrale proximally and with metacarpal 
8361 and 2 distally. Distal carpal 3 is slightly smaller than distal carpal 4, and the two elements

837 articulate with metacarpal III and IV, respectively.

838 There are four digits in the manus, the pattern seen in most salamanders. Digit 3 is the

839 longest, having an extra phalange in comparison to the other digits. The phalangeal formula is 2-

840 2-3-2, a generalized pattern for most salamanders (Shubin \& Wake, 2003). The terminal phalanx

841 of each digit is covered with a cornified sheath, possibly an adaptive feature correlated to living

842 in a mountain stream environment.

843

844 Pelvic girdle and hind limbs

845 The pelvis in Batrachuperus londongensis displays the usual pattern that occurs in most other

846 salamanders: the paired ilia and ischia are ossified, whereas the pubis remains cartilaginous (but

847 see below). In addition, the ypsiloid cartilage is present as in some but not all salamanders (see

848 Hecht \& Edwards, 1976, 1977). The ilium is roughly club-shaped, with a slightly thickened and

849 expanded ventral plate and a narrow dorsal blade. The ventral plate contributes to a large part of

850 the acetabulum and is ventrally in articulation with the ischium. The iliac blade is connected

851 with the sacral rib by a ligament. The bone is set in a more or less vertical position, whereas the

852 iliac blade is slightly inclined posteriorly.

853 The ischium is a large bony plate that is the main ventral element in the pelvis. The two

854 ischial plates meet ventrally to form a symphysal hinge articulation along the midline. In ventral

855 view, the ischium is anteriorly widened with a rounded border, to which the cartilaginous pubis

856 is attached (but see below), but projects laterally at the posteroventral border of the acetabulum.

857 Immediately posterior to the acetabulum, the lateral border of the plate is deeply notched

858 between the acetabulum and a large posterolateral process (ischial spine). The latter process 
859 serves as origin of the flexor of the tail, M. ischio-caudalis (Francis, 1934). The elongate ischial

860 spine is significantly different from that in the type species B. pinchonii, in which the spine is

861 rudimentary (see Zhang et al., 2009).

862 The pubis often remains cartilaginous, as observed in several specimens (CIB 14482,

863 14484, 14485, 14487, 14507); however, in other specimens (CIB 65I0013/14380, 14381, 14504,

864 14509), the pubis is partly ossified, evidenced by the presence of a robust process anteroventral

865 to the acetabulum (Fig. 10A-D; Fig. S5). This interpretation is supported by the presence of an

866 obturator foramen at the base of the process, which marks the border between the pubis and

867 ischium (Fig. 10B). In addition, two of these specimens (CIB 14381, 14509) show that the

868 fusion of the ossified part of pubis to the ischium is not yet completed; thus, in these two

869 specimens the obturator foramen is still partly open anteromedially (Fig. 10D). In them, the

870 large ventral plate in the pelvis actually represents the ossification of the ischium and at least a

871 part of the pubis, and can best be termed a pubio-ischium.

872 It is also interesting to note that many specimens including the holotype display a second

873 pair of small foramina more posteriorly located at the base of the ischial spine (Fig. 10B,D,F,H).

874 To our knowledge, there are no publications that figured or described this pair of foramina, but

875 they are indeed present in both neotenic and postmetamorphic individuals of Batrachuperus

876 londongensis.

877 A Y-shaped cartilage (ypsiloid) is not shown in CT-scanned images, but is observed in

878 cleared and stained specimens (Fig. S5). This cartilage has been shown to be correlated with the

879 hydro-static function of the lungs (Whipple, 1906); that is, the salamander can easily raise its

880 head in the water by elevating the ypsiloid cartilage, thereby compressing the lower abdomen

881 and forcing the air in the lungs forwards to the anterior end; conversely, the salamander is able to 
882 depress its head by lowering the ypsiloid cartilage, returning the air to the posterior portion of the

883 lungs, enabling the animal to swim to deeper water. The ypsiloid cartilage is present in

884 Hynobiidae, Cryptobranchidae, Salamandridae, and Ambystomatidae, but absent in Proteidae,

885 Plethodontidae, Sirenidae, and Amphiumidae (Hecht \& Edwards, 1976, 1977).

886 The femur is a robust element roughly the same length as the humerus. As seen in the

887 holotype and several other specimens (CIB 65I0013/14380, 14381, 14504, 14507, 14509), the

888 strongly expanded proximal end bears a large bony condyle in articulation with the acetabulum

889 (Fig. 10I-L). In four other specimens (CIB 14482, 14484, 14485, 14487), however, the femur is

890 capped with cartilage; thus, CT images of these specimens display a gap between the femur and

891 acetabulum. On the extensor side, the femur bears a longitudinal ridge, extending from the

892 proximal end to the fibular condyle; this ridge serves as insertion of the M. pubo-ischio-

893 femoralis internus, a powerful extensor of the thigh (Francis, 1934). Posterior to this ridge and

894 close to the proximal end, a small tubercle marks the external trochanter (Fig. 10I,O), onto which

895 the M. caudalis-femoralis inserts (Francis, 1934). On the flexor side, the robust femoral

896 trochanter projects ventromedially as a twig-like process (Fig. 10I-P), onto which the M. pubo-

897 ischio-femoralis externus attaches (Ashley-Ross, 1992). The trochanteric crest extends from the

898 femoral trochanter distally along the shaft to the tibial condyle. On the distal end, both the tibial

899 and fibular condyles are well ossified to display a bony articulation with their corresponding

900 elements. The tibial condyle is much larger than the fibular condyle. As described above for the

901 proximal head, in some specimens (CIB 14482, 14484, 14485, 14487) the tibial and fibular

902 condyles are poorly ossified, with slightly concave depressions as indicative of a cartilage-

903 capped epiphysis. 
The tibia and fibula are similar in length, but the former element is the more robust (Fig.

905 11). Proximally on its extensor aspect, the tibia bears a weakly developed tibial crest that serves 906 as a tendinous insertion of the M. extensor ilio-tibialis (Francis, 1934). Along the distal half of

907 the tibia is a well-defined bony ridge facing the fibula; this medial ridge probably serves as 908 insertion of the M. extensor cruris tibialis (Ashley-Ross, 1992). At the proximal end of the 909 medial ridge, a small but twig-like process provides a tendinous insertion of the M. pubo-ischio910 tibialis (Francis, 1934). The lateral side of the fibula is straight but the medial side concave, with 911 its distal end expanded medially to articulate with the tibia.

912 Maximum ossification of the mesopodium includes as many as nine tarsal elements (Fig.

913 11). As observed in several specimens (CIB 65I0013/14380, 14381, 14485, 14509), the

914 intermedium is a large element with its proximal process wedged between the tibia and fibula;

915 the intermedium distally articulates with a single centrale. The fibulare is roughly the same size 916 as the intermedium and is medially in extensive articulation with the latter. The tibiale is much 917 smaller than the fibulare, but medially articulates with the centrale. Among distal elements, 918 element $\mathrm{y}$ is more or less rounded, in articulation with the tibiale proximally, and with a large 919 basale commune laterally. Distal tarsal 3 and 4 are similar in size and both are in contact with 920 the centrale. Distal tarsal 5 is missing, what is likely related to the loss of digit 5 . Distolaterally, 921 the postminimus is a small bone in contact with both the fibulare and metacarpal IV. According 922 to Shubin \& Wake (2003), a postminimus is present in Batrachuperus and several other 923 hynobiids (Liua, Ranodon, Salamandrella, Paradactylodon), and also in the cryptobranchid 924 Andrias.

925 Several other specimens show less extensive ossification in the mesopodium than those 926 described above. As observed in four specimens (CIB 14482, 14482, 14484, 14487), all those 
927 elements ossified already show essentially the same arrangement pattern as described above, but

928 have one or two of the preaxial elements (tibiale and element y) still unossified. In addition, in

929 none of these specimens is the postminimus ossified. Comparison of these specimens with those

930 described above indicates that element y ossifies before the tibiale, whereas the postminimus is

931 ossified after the tibiale; thus, the postminimus is the last tarsal element to be ossified

932 ontogenetically.

933 As in all congeneric species, Batrachuperus londongensis displays a reduction of hind

934 limb digits from five to four, with digit 5 missing. The phalangeal formula is $2-2-3-2$, except for 935 two specimens (CIB 14484, 14504) that show developmental abnormalities (see below). The 936 terminal phalanges are covered with a cornified sheath as occurs commonly in other mountain 937 stream salamanders, including the Middle Eastern stream salamander Paradactylodon (Kami, 938 1999).

939 As mentioned above, two specimens (CIB 14484, 14504) show developmental

940 abnormalities in the hind limb. In CIB 14484, the right foot has four digits, but five in the left.

941 In keeping with the presence of digit 5 , a distal tarsal 5 is also present in the left foot but not in

942 the right. The digital formula in this specimen is $2-2-2-2-2$ in the right foot, and 2-2-3-2 in the

943 left. The other specimen (CIB 14504) has only three digits in left foot, with digit 1 entirely

944 missing; but there are four digits in the right. The left foot has only six tarsal elements, whereas

945 the right has ten, including two centralia. The six tarsals in the left may reflect abnormal fusion

946 of several bones: possibly fusion of the intermedium with the centrale, and fusion of distal tarsals

$9472+3$. The fibulare is enlarged and roughly the same size as the intermedium. Both left and right

948 limbs have a small postminimus, indicative of this individual being a fully grown adult. The

949 digital formula of this specimen is ?-2-3-2 for the left foot, and is 2-2-2-2 for the right. 
950

\section{Discussion}

952 The Longdong Stream Salamander, Batrachuperus londongensis, is a rare hynobiid species that

953 is of special interest because of a life-history that features facultative neoteny. In addition,

954 undertaking an osteological study of this salamander is urgent, because of its rarity and current

955 vulnerability to extinction (Jiang et al., 2016). From comparison with other species of the genus

956 and other hynobiids, our study has revealed several osteological features that are diagnostic of $B$.

957 londongensis, while several other features are shown to be of developmental, ecological, or

958 phylogenetic significance. We provide a discussion of these results below.

959

\section{Osteological characterization of Batrachuperus londongensis}

961 Previously, Batrachuperus londongensis had been diagnosed with reference only to external

962 morphological characters and the number of chromosomes (Liu \& Tian, 1978; Fei, Ye \& Tian,

963 1983; Fei et al., 2006). In supplementing the diagnosis of this species by inclusion of

964 osteological features, our study shows that some of these diagnostic features are also

965 phylogenetically significant in respect to both hynobiids and to the evolution of salamanders

966 more generally. Osteologically, B. londongensis shares with its congeneric species the following

967 derived characters: the maxilla is extremely short, posteriorly terminating at a level anterior to

968 midlevel of the orbit; the lacrimal extends anteriorly over the border of the external naris, but not

969 over the orbital border posteriorly (except for B. taibaiensis); a nasal-maxillary contact is absent

970 because the two elements are separated by the lacrimal; the otic process of the pterygoid has no

971 bony contact with the parasphenoid (except for $B$. yenyuanensis); the ceratohyal is distally

972 ossified; a single centrale (except for B. yenyuanensis) in the manus is in direct contact with the 
973 radius, preventing the radiale from contacting the intermedium; the number of digits is reduced

974 from five to four in the pes (shared with Salamandrella and Paradactylodon as homoplasies);

975 terminal phalanges are covered with a cornified sheath (shared with Onychodactylus, Liua,

976 Paradactylodon as ecological homoplasies).

977 Batrachuperus londongensis is distinguished from B. pinchonii and all other congeneric

978 species by a combination of the following characters: alary process of premaxilla barely

979 contributing to border of anterodorsal fenestra (shared with B. tibetanus); suture between nasal

980 and frontal located at the level of anterior border of orbit; vomers do not contact at the midline

981 (unique); vomerine teeth four to eight in number, arranged in a straight line that is nearly

982 vertically oriented; the ascending process of the palatoquadrate is ossified as a pillar between the

983 parietal and the otic process of the pterygoid (shared with B. tibetanus and B. taibaiensis); radial

984 loops stemming from basibranchial I do not cross one another (shared with B. pinchonii, $B$.

985 tibetanus; unknown for other species); cartilaginous hypobranchial I and ceratobranchial I

986 remain separate (fused in B. pinchonii and B. tibetanus); presacral vertebrae 18 in number; the

987 scapular blade is extremely short, with a prominent posterodorsal process (unique); the ischial

988 plate is penetrated by a small nerve foramen, and the ischial spine is clearly more elongated than

989 in other species.

990

991 Developmental features related to life-history differences

992 As stated above (see Introduction), Batrachuperus londongensis may represent the only living

993 hynobiid that is facultatively neotenic, as both biphasic individuals and neotenes ("permanent

994 larval producers" of Rose, 2003) are known for the species. Based on our study of both neotenic 
995 postmetamorphic specimens, we provide a discussion of life-history differences of the species as 996 presented below.

997 In terms of body size, neotenes tend to be larger than postmetamorphic individuals. The 998 holotype CIB 65I0013/14380 (TL=265 mm) is the largest individual known for the species, but 999 still retains gill slits and a larval configuration of the hyobranchium (Fei et al., 2006). Because 1000 many relatively small specimens $(\mathrm{TL}=162-241 \mathrm{~mm})$ have completed metamorphosis, the 1001 presence of external gill slits and retention of a larval hyobranchium in large individuals cannot 1002 be logically interpreted as ontogenetic features always leading to metamorphosis in 1003 Batrachuperus londongensis. By contrast, the holotype and several other large individuals 1004 display fully ossified limbs and a postminimus in the pes, thereby giving a clear indication that 1005 these are fully grown adults, in spite of their retention of some larval features.

1006 The most striking morphological difference between neotenic and postmetamorphic 1007 individuals is seen in the hyobranchium. As figured in Fei et al. (2006: fig. 69f, g), neotenes 1008 always display a more complex hyobranchium than do postmetamorphic individuals, in which 1009 ceratobranchials III and IV are entirely missing. Among median elements, the inverted "T1010 shaped" basibranchial II occurs in both postmetamorphic and neotenic forms, whereas the 1011 "fork"-shaped pattern is seen only in some neotenes as a developmental feature. We provide a 1012 possible interpretation here: the "fork"-shaped pattern can be viewed as the initial larval pattern, 1013 with the posterior branches subsequently absorbed at metamorphosis, whereas in neotenes the 1014 absorption process is prolonged or delayed. This interpretation is supported by evidence that 1015 large neotenic individuals, including the holotype CIB 65I0013/14380, which display the 1016 inverted " $T$ "-shaped pattern, still have a remnant of the posterior processes, whereas slightly 1017 smaller and presumably younger adults show the "fork"-shaped pattern. 

individuals show incomplete ossification of the ceratohyal, with large neotenes displaying more extensive ossification than smaller ones. This observation indicates that ossification of the

1021 ceratohyal terminates at metamorphosis, but continues in neotenes. Hypobranchial I is partly

1022 ossified in large neotenes, but the element is missing in typical postmetamorphic forms (see

1023 below). Ceratobranchial I is partly ossified only in neotenes. Evidently, ossification of the first 1024 branchial arch derivatives is terminated at metamorphosis, but is prolonged in neotenes.

1025 Ossification of hypobranchial II and ceratobranchial II is a common pattern in all hynobiids, 1026 whereas ceratobranchials III and IV are retained only in neotenic individuals, and are normally 1027 absent in postmetamorphic forms. CIB 14487 is a relatively small postmetamorphic adult, but it 1028 retains a remnant part of the ceratobranchial III bilaterally. Comparison of this specimen with 1029 those that show the typical postmetamorphic pattern of the hyobranchium indicates that 1030 resorption of larval arches can be prolonged until after metamorphosis is otherwise completed.

1031

\section{Partial ossification of ceratohyal in hynobiids}

1033 Comparison of Batrachuperus londongensis with congeneric species and other hynobiids 1034 suggests that partial ossification of the ceratohyal is a feature of phylogenetic significance. 1035 Within Batrachuperus, a similar pattern of ossification of the ceratohyal occurs in B. tibetanus 1036 (FMNH 5901), B. pinchonii (Zhang et al., 2009: fig. 24), B. karlschmidti (FMNH 49380), B. 1037 yenyuanensis (FMNH 49371), and B. taibaiensis (CIB 20040235). Xiong et al. (2013b: fig. 1E 1038 and $1 \mathrm{H}$ ) illustrated B. pinchonii and Liua shihi as having the ceratohyal entirely cartilaginous, 1039 but characterized this structure in the description as partly ossified in both species. Based on our 
1040 own observations, we conclude that partial ossification of the ceratohyal occurs in all species of 1041 Batrachuperus.

1042 In other hynobiids, partial ossification of the ceratohyal occurs in the monotypic 1043 Pachyhynobius shangchengensis and in Ranodon sibiricus (Fei \& Ye, 1983; Fei et al., 2006; 1044 however, Xiong et al., 2013b: fig. $1 \mathrm{G}$ shows no ossification in R. sibiricus), and in Liua shihi 1045 (Zhang, 1985; Fei et al., 2006; contra Xiong et al., 2013b: fig. 1, but mentioned as partly ossified 1046 in the description). In addition, our observation of a specimen of Paradactylodon mustersi 1047 (FMNH 211936) shows that it also displays a partly ossified ceratohyal. Another species, 1048 Paradactylodon persicus (MVZ 241494; AmphibiaTree, 2004) shows no ossification of the 1049 ceratohyal, but the specimen seems to be a young adult, as the nasals do not yet fully meet at the 1050 midline and a small parietal fontanelle is not yet completely closed. Ossification of the 1051 ceratohyal in four hynobiid genera (Onychodactylus, Salamandrella, Pseudohynobius, Hynobius) 1052 has yet to be recorded.

1053 In the closely related clade Cryptobranchidae, the distal end of the ceratohyal is ossified 1054 in the North American hellbender Cryptobranchus alleganiensis (Elwood \& Cundall, 1994: fig. 1055 9; Rose, 2003: fig. 5), but not in the Chinese or Japanese giant salamander Andrias (Sato, 1943; 1056 Aoyama, 1930; Wu, 1982; Rose, 2003). Among non-cryptobranchoid salamanders, partial 1057 ossification of the ceratohyal is seen in some salamandrids (e.g., Notophthalmus viridescens) and 1058 some dicamptodontids (e.g., Dicamptodon ensatus), in Siren and Pseudobranchus, and in 1059 Proteus but not in Necturus (see Rose, 2003 for citations). Clearly, the distribution of this 1060 character needs to be scrutinized in a cladistic analysis to understand its phylogenetic 1061 significance. 


\section{Ossification patterns of mesopodial elements and reduction of number of}

\section{4 digits}

1065 Salamander limbs display variant structural patterns that provide significant information for 1066 addressing questions of morphological evolution in terms of ecological adaptation (Shubin \& 1067 Wake, 2003). In this context, several limb features of Batrachuperus londongensis, including 1068 the arrangement of mesopodial elements and the reduction of the number of digits, are worth 1069 consideration in comparison with other congeneric species and other hynobiids as well. Patterns of limb structure in hynobiid salamanders have been documented for several 1071 genera (Onychodactylus, Batrachuperus, Salamandrella, Liua, Ranodon, Paradactylodon), but 1072 remain largely unknown or poorly known for several others (Hynobius, Pachyhynobius, 1073 Pseudohynobius). Batrachuperus has been regarded as having two centralia (Shubin \& Wake, 1074 2003), but this interpretation was probably based on B. yenyuanensis, which indeed has two 1075 centralia; however, this study revealed that all other species of the genus, including the type 1076 species B. pinchonii, have a single centrale in both manus and pes. Although the single centrale 1077 is in direct contact with the radius in the forelimb, it does not contact the tibia in the hind limb. 1078 A direct contact of the centrale with the radius has been recognized as a peculiar feature in extant 1079 salamanders, as it also occurs in some lepospondyls and temnospondyls (Carroll, 1968; Carroll 1080 \& Gaskill, 1978; Shubin \& Wake, 2003). Regardless, B. yenyuanensis is the only species within 1081 Batrachuperus that possesses two centralia. Phylogenetic analysis based on molecular data has 1082 shown that B. yenyuanensis occupies a basal position in relation to other species of the genus 1083 (Chen et al., 2015); thus, the single centrale in these other species is likely to be a derived state 1084 acquired within Batrachuperus. Among other hynobiids, retention of two centralia is known for 
1085 several taxa, including Liua, Ranodon, Salamandrella, and Paradactylodon (Shubin \& Wake, 1086 2003).

1087 Comparison of specimens of Batrachuperus species reveals a delayed ossification of 1088 preaxial elements in both fore- and hind limbs. In the forelimb, fully grown adults of $B$. 1089 londongensis (e.g., holotype CIB 65I0013/14380, 14381, 14482, 14504) have a large radiale, 1090 which probably reflects fusion of the radiale with element y, whereas young adults (e.g., CIB $109114484,14485,14487$ ) show no ossification of the radiale or element $y$. Whether the radiale and 1092 element y are co-ossified or fused together in fully grown adults needs to be verified by 1093 developmental evidence. In the hind limb, fully grown adults (e.g., CIB 65I0013/14380, 14381, $109414504,14507,14509)$ clearly show that the tibiale and element y are ossified as separate 1095 elements, with several young adults (e.g., CIB 14482, 14484, 14485) showing that element y is 1096 ossified before the tibiale. Comparisons with other species of Batrachuperus and other 1097 hynobiids are needed to understand the ontogenetic and phylogenetic significance of these 1098 patterns.

According to Shubin \& Wake (2003), a postminimus is present in Batrachuperus, several 1100 other genera of hynobiid salamanders (Onychodactylus, Liua, Ranodon, Salamandrella, 1101 Paradactylodon), and also the cryptobranchid genus Andrias. Comparison of specimens of 1102 congeneric species in this study leads us to concur with Shubin \& Wake (2003) in that 1103 congeneric species in Batrachuperus indeed have a postminimus in pes, and this is probably the 1104 last limb element to be ossified ontogenetically, as the postminimus is observed in fully grown 1105 adults but not in those young adults that have element $y$, or element y and tibiale ossified (see 1106 above). The postminimus is absent in Hynobius, Pachyhynobius, and Pseudohynobius (Shubin 1107 \& Wake, 2003). Although relevant information on presence/absence of this element is still 
1108 sketchy for some hynobiid taxa, we interpret that possession of a postminimus as a

1109 plesiomorphic feature because it is widely distributed in the family Hynobiidae. However, how

1110 many taxa at generic level share the loss of the element as a homology, or independent loss of

1111 this element need to be scrutinized in a thorough phylogenetic analysis.

1112 Finally, Batrachuperus londongensis displays limb patterns commonly seen in other

1113 mountain stream salamanders: The number of digits is reduced from five to four in hind limb,

1114 and terminal phalanges in both fingers and toes are covered with a cornified sheath. These

1115 features have been recognized as corresponding to ecological adaptations of the salamanders to

1116 higher altitude mountain stream environments (Fei \& Ye, 1984). These limb features are

1117 commonly seen in all other Batrachuperus species, and in other hynobiids (Salamandrella,

1118 Paradactylodon, and some species of Hynobius), which are also mountain stream dwellers

1119 (Reilly, 1983; Fei et al., 2006). Interestingly, there are some hynobiids (Onychodactylus,

1120 Ranodon, Liua) that are mountain stream dwellers, but none of these show reduction of digits

1121 from five to four in the pes; and Onychodactylus is the only genus other than those mentioned

1122 above has developed claw-like terminal phalanges with a cornified sheath (Fei et al., 2006).

1123

\section{Conclusions}

1125 Our study of the osteological anatomy of Batrachuperus londongensis has led to the following 1126 conclusions:

1) Batrachuperus londongensis is diagnosed by a set of osteological features, including

1128 unique features: alary process of premaxilla is excluded from the border of the anterodorsal

1129 fenestra; vomers lack medial contact; parasphenoid enters anteromedial fenestra; vomerine tooth 
1130 row nearly vertical in position; presacral vertebrae 18 in number; scapular blade develops a

1131 distinct posterodorsal process.

1132 2) B. londongensis is among the few hynobiids that display perichondral ossification of

1133 the ascending process of the palatoquadrate as a part of the suspensorium.

1134 3) A stapedial foramen is unexpectedly present in some but not all specimens, an unusual

1135 feature that needs to be thoroughly investigated.

1136 4) Neotenic individuals display a more complex structural pattern of the hyobranchium

1137 than postmetamorphic individuals, most notably the retention of ceratobranchials III and IV.

1138 Neotenes also show increased ossification of hyobranchial elements during aging, in contrast to

1139 loss of elements by resorption in metamorphic individuals.

1140 5) B. londongensis has a single centrale in direct contact with the radius in the manus, but

1141 not with the corresponding element, the tibia, in the pes. In both fore- and hind limbs, delayed

1142 ossification of preaxial elements is a common pattern in both neotenes and postmetamorphic 1143 specimens.

1144 6) B. londongensis retains element y and the postminimus in the pes as a plesiomorphic

1145 pattern in hynobiids. Phylogenetic significance of the retention or loss of these limb elements

1146 within Hynobiidae requires a thorough investigation.

1147

1148 Acknowledgements

1149 We thank Alan Resetar (Field Museum of Natural History) for access to comparative specimens

1150 under his care, and Zhe-Xi Luo (University of Chicago, Chicago, USA) for use of the CT

1151 scanner in his laboratory. Professor RC Fox (University of Alberta, Edmonton, Canada) read

1152 and commented on the manuscript, and Yu-long Li (Chengdu Institute of Biology, Chinese 
1153 Academy of Sciences, Chengdu, China) helped with CT scanning of some specimens. We also

1154 thank Neil Shubin (University of Chicago) for discussion on ossification patterns and evolution

1155 of the mesopodium in salamanders. Two reviewers (M. Laurin and J. Ziermann) provided

1156 constructive comments and suggestions that lead to improvement of our manuscript.

1157

1158

1159 REFERENCES

1160 AmphibiaTree. 2004. Batrachuperus persicus (On-line), Digital Morphology. Accessed March

1161

1162 AmphibiaTree. 2008. "Ambystoma gracile" (On-line), Digital Morphology. Accessed April 5, 2017 at http://digimorph.org/specimens/Ambystoma_gracile/head/.

1164 AmphibiaWeb. 2017. <http://amphibiaweb.org> University of California, Berkeley, CA, USA. 1165 (accessed 10 March 2017).

1166 Aoyama F.1930. Die Entwicklungsgeschichte des Kopfskelettes des Cryptobranchus japonicus. 1167 Zeitschrift für Anatomie und Entwicklungsgeschichte 93:106-181.

1168 Ashley-Ross MA. 1992. The comparative myology of the thigh and crus in the salamanders 1169 Ambystoma tigrinum and Dicamptodon tenebrosus. Journal of Morphology 211:147-163. DOI: $10.1002 /$ jmor.1052110204.

1171 Boulenger GA. 1878. Description de deux genres nouveaux de la famille des salamandrides. Bulletin de la Société Zoologique de France 3:71-71.

1173 Carroll RL. 1968. The postcranial skeleton of the Permian microsaur Pantylus. Canadian $1174 \quad$ Journal of Zoology 46:1175-1192. 
1175 Carroll RL, Gaskill P. 1978. The order Microsauria. Memoirs of the American Philosophical 1176 Society 126:1-211.

1177 Carroll RL, Holmes R. 1980. The skull and jaw musculature as guides to the ancestry of

1178

1179

1180

1181

1182

1183

1184

1185

1186

1187

1188

1189

1190

1191

1192

1193

1194

1195

1196

1197 salamanders. Zoological Journal of the Linnean Society 68:1-40. DOI: 10.1111/j.10963642.1980.tb01916.x

Chen J, Gao KQ. 2009. Early Cretaceous hynobiid Liaoxitriton zhongjiani (Amphibia: Caudata) from Liaoning, China, and the monophyly of the Hynobiidae. Journal of Vertebrate Paleontology 29 (supplement to no. 3):76A. DOI: 10.1080/02724634.2009.10411818.

Chen MY, Mao RL, Liang D, Kuro-o M, Zeng XM, Zhang P. 2015. A reinvestigation of phylogeny and divergence times of Hynobiidae (Amphibia, Caudata) based on 29 nuclear genes. Molecular Phylogenetics and Evolution 83:1-6. DOI: 10.1016/j.ympev.2014.10.010.

Cloete SE. 1961. The cranial morphology of Rhyacotriton olympicus olympicus (Gaige). Annals of the University of Stellenbosch 36A:113-145.

Cope ED. 1859. On the primary divisions of the Salamandridae, with descriptions of two new species. Proceedings of the Academy of Natural Sciences of Philadelphia 11:122-128.

David A. 1872 (1871). Rapport adressé a MM. les Professeur-Administráteurs du Museum d'histoire naturelle. Nouvelles Archives du Muséum d'Histoire Naturelle. Paris 7:75-100.

De Beer GR. 1937. The Development of the Vertebrate Skull. Oxford: the Clarendon Press.

Duellman WE, Trueb L. 1986. Biology of Amphibians. New York: McGraw-Hill Book Company.

Duméril AMC. 1806. Zoologie analytique, ou méthode naturelle de classification des animaux, rendue plus facile à l'aide de tableaux synoptiques. Paris: Allais. 
1198 Dunn ER. 1922. The sound-transmitting apparatus of salamanders and the phylogeny of the 1199 Caudata. American Naturalist 56:418-427. DOI 10.1086/279882.

1200 Dunn ER. 1923. The salamanders of the family Hynobiidae. Proceedings of the American 1201 Academy of Arts and Sciences 58:445-523. DOI: 10.2307/20026019.

1202 Edwards JL. 1976. Spinal nerves and their bearing on salamander phylogeny. Journal of 1203 Morphology 148:305-328. DOI: 10.1002/jmor.1051480304.

1204 Elwood JRL, Cundall D. 1994. Morphology and behavior of the feeding apparatus in 1205 Cryptobranchus alleganiensis (Amphibia: Caudata). Journal of Morphology 220: 47-70.

1206 DOI: 10.1002/jmor.1052200106.

1207 Erdman S, Cundall D. 1984. The feeding apparatus of the salamander Amphiuma tridactylum: morphology and behavior. Journal of Morphology 181:175-204.

1209 Estes R. 1981. Encyclopedia of Paleoherpetology, Part 2: Gymnophiona, Caudata. Stuttgart: 1210 Gustav Fischer Verlag.

1211 Fei L, Ye C. 1983. Systematic studies on Hynobiidae, including diagnosis of a new genus Pseudohynobius (Amphibia: Caudata). Acta Herpetologica Sinica 2: 31-37. (in Chinese

1214 Fei L, Ye C. 1984. On the geographical-distribution, center of differentiation and phylogeneticrelationships of the different genera of Hynobiidae (Amphibia, Salamandriformes). Acta Zoologica Sinica 30:385-392. (in Chinese with English abstract).

Fei L, Ye C. 2001. The Color Handbook of the Amphibians of Sichuan. Chengdu, China: Sichuan Forestry Department, Sichuan Association of Wildlife Conservation, and Chengdu

1220 Fei L, Ye C. 2017. Amphibians of China (Vol. I). Beijing: Science Press. 
1221 Fei L, Ye C, Tian W. 1983. Systematic discussion on the genus Batrachuperus with description

1222

1223

1224

1225

1226

1227

1228

1229

1230

1231

1232

1233

1234

1235

1236

1237

1238

1239

1240

1241 of a new species. Acta Zootaxonomica Sinica 8:209-219. (in Chinese with English abstract).

Fei L, Hu S, Ye C, Huang Y. 2006. Fauna Sinica Amphibia volume 1. Beijing: Science Press (in Chinese with English abstract).

Fei L, Ye C, Jiang J. 2010. Colored Atlas of Chinese Amphibians. Chengdu: Sichuan Publishing Group.

Fei L, Ye C, Jiang J. 2012. Colored Atlas of Chinese Amphibians and Their Distributions. Chengdu: Sichuan Publishing Group.

Fox H. 1959. A study of the development of the head and pharynx of the larval urodele Hynobius and its bearing on the evolution of the vertebrate head. Philosophical transactions of the Royal Society of London. Series B, Biological Sciences 242:151-204. URL: http://www.jstor.org/stable/2992618.

Francis ETB. 1934. The Anatomy of the Salamander. Oxford: Clarendon Press.

Frost DR. 2017. Amphibian Species of the World: an Online Reference. Version 6.0. (accessed 4 March 2017). Electronic Database accessible at http://research.amnh.org/herpetology/amphibia/index.html. American Museum of Natural History, New York, USA.

Fu J, Zeng X. 2008. How many species are in the genus Batrachuperus? A phylogeographical analysis of the stream salamanders (family Hynobiidae) from southwestern China. Molecular Ecology 17(6):1469-1488. DOI: 10.1111/j.1365-294X.2007.03681.x. 
1242 Fu J, Wang Y, Zeng X, Liu Z, Zheng Y. 2001. Genetic diversity of Eastern Batrachuperus

1243 (Caudata: Hynobiidae). Copeia 2001 (4):1100-1107. DOI: 10.1643/0045-

1244 8511(2001)001[1100:GDOEBC]2.0.CO;2.

1245 Fukuda Y. 1930. Die Veränderungen des Hyobranchialskeletts vom Onychodactylus japonicus 1246 bei der Metamorphose. Folia Anatomica Japonica 9:47-72.

1247 Gao KQ, Shubin NH. 2001. Late Jurassic salamanders from northern China. Nature 410:5741248 577. DOI: $10.1038 / 35069051$.

1249 Gao KQ, Shubin NH. 2003. Earliest known crown-group salamanders. Nature 422:424-428.

$1250 \quad$ DOI: $10.1038 /$ nature01491.

1251 Gao KQ, Shubin HN. 2012. Late Jurassic salamandroid from western Liaoning, China.

$1252 \quad$ Proceedings of the National Academy of Sciences of the United States of America

1253 109:5767-5772. DOI: 10.1073/pnas.1009828109.

1254 Gao KQ, Chen J, Jia J. 2013. Taxonomic diversity, stratigraphic range, and exceptional 1255 preservation of Juro-Cretaceous salamanders from northern China. Canadian Journal of

1256 Earth Sciences 50:255-267. DOI: 10.1139/e2012-039.

1257 Gaupp E. 1898. Ontogenese und Phylogenese des schalleitenden Apparates bei den Wirbeltieren. 1258 Ergebnisse der Anatomie und Entwicklungsgeschichte VIII:990-1149.

1259 Gaupp E. 1911. Über den N. trochlearis der Urodelen und über die Austrittsstellen der 1260 Gehirnnerven aus dem Schädelraum im allgemeinen. Anatomischer Anzeiger 38:4011261 444.

1262 Goodrich ES. 1930. Studies on the Structure and Development of Vertebrates. Chicago: The 1263 University of Chicago Press. 
1264 Hanken J, Wassersug R. 1981. The visible skeleton: A new double-stain technique reveals the 1265 nature of the "hard" tissues. Functional Photography 16:22-26.

1266 Hecht MK, Edwards JL. 1976. The determination of parallel or monophyletic relationships: the 1267 proteid salamanders- a test case. The American Naturalist 110:653-677. DOI:

1268 $10.1086 / 283096$.

1269 Hecht MK, Edwards JL. 1977. The methodology of phylogenetic inference above the species 1270 level. In: Hecht MK, Goody PC, Hecht BM, eds. Major Patterns in Vertebrate Evolution, New York and London: Plenum Press, 3-51.

1272 Inukai T. 1930-1932. Urodelenarten aus Nord Japan mit besonderer Berüucksichtigung der Morphologie des Schädels. Journal of the Faculty of Science, Hokkaido University,

1275 ICZN, 1999. International Code of Zoological Nomenclature. $4^{\text {th }}$ edition, published by the 1276 international Trust for Zoological Nomenclature 1999.

IUCN, 2016. The IUCN Red List of Threatened Species. Version 2016-2. www.iucnredlist.org. Downloaded on 30 October 2016.

Ivachnenko M. 1978. Urodeles from the Triassic and Jurassic of Soviet Central Asia. Paleontological Journal 1978:362-368.

1281 Jia J, Gao KQ. 2016a. A new hynobiid-like salamander (Amphibia, Urodela) from Inner 1282 Mongolia, China, provides a rare case study of developmental features in an Early Cretaceous fossil urodele. PeerJ 4:e2499; DOI: 10.7717/peerj.2499.

1284 Jia J, Gao KQ. 2016b. A new basal salamandroid (Amphibia, Urodela) from the Late Jurassic of 1285 Qinglong, Hebei Province, China. PLoS ONE 11:e0153834. DOI: 10.1371/journal.pone.0153834. 
1287 Jiang Z, Jiang J, Wang Y, Zhang E, Zhang Y, Li L, Xie F, Cai B, Cao L, Zheng G, Dong L,

1288 Zhang Z, Ding P, Luo Z, Ding C, Ma Z, Tang S, Cao W, Li C, Hu H, Ma Y, Wu Y,

1289 Wang Y, Zhou K, Liu S, Chen Y, Li J, Feng Z, Wang Y, Wang B, Li C, Song X, Cai L,

1290 Zang C, Zeng Y, Meng Z, Fang H, Ping X. 2016. Red list of China’s vertebrates.

1291 Biodiversity Science 24:500-553.

1292 Jömann N, Clemen G, Greven H. 2005. Notes on cranial ontogeny and delayed metamorphosis 1293 in the hynobiid salamander Ranodon sibiricus Kessler, 1866 (Urodela). Annals of

1294 Anatomy 187:305-431. DOI: 10.1016/j.aanat.2005.02.010.

1295 Kami HG. 1999. Additional specimens of the Persian Mountain Salamander, Batrachuperus 1296

1297

1298 persicus, from Iran (Amphibia: Hynobiidae). Zoology in the Middle East 19(1):37-42. DOI: 10.1080/09397140.1999.10637794. url: http://dx.doi.org/10.1080/09397140.1999.10637794

1299 Kingsbury BF, Reed HD. 1909. The columella auris in Amphibia. Second Contribution. Journal 1300 of Morphology 20:549-628. DOI: 10.1002/jmor.1050200403.

1301 1302 1303 1304 1305 1306 1307 1308 1309
Laboratory of Amphibians and Reptiles, Biological Institute of Sichuan Province. 1977. A Systematic Checklist of Chinese Amphibians. Beijing: Science Press, 1-97. (in Chinese)

Larson, JHJ, Beneski JTJ, Miller BT. 1996. Structure and function of the hyolingual system in Hynobius and its bearing on the evolution of prey capture in terrestrial salamanders. Journal of Morphology 227:235-248. DOI: 10.1002/(SICI)10974687(199602)227:2<235:AID-JMOR>3.0.CO;2-7.

Lebedkina NS. 1964. The development of the dermal bones of the basement of the skull in Urodela (Hynobiidae). Trudy Akademiia Nauk SSSR 33:75-172.

Lebedkina NS. 2004. Evolution of the Amphibian Skull. Moscow: Pensoft Publishers. 
1310 Litvinchuk SN, Borkin LJ. 2003. Variation in number of trunk vertebrae and in count of costal

1311

1312

1313

1314

1315

1316

1317

1318

1319

1320

1321

1322

1323

1324

1325

1326

1327 1328

1329

1330

1331

1332 grooves in salamanders of the family Hynobiidae. Contributions to Zoology 72: 195-209. url: http://dpc.ubs.uva.nl/vol72/nr04/a01

Liu CC. 1950. Amphibians of Western China. Chicago Natural History Museum Fieldiana Zoology Memoirs 2:1-400.

Liu CC, Tian WS. 1978. In Liu CC, Hu SQ, Tian WS, Wu GF. 1978: Four new amphibian species from Sichuan and Guangxi. Materials for Herpetological Research Chengdu 4:18-19.

Liu CC, Tian WS. 1983. In Fei L, Ye CY, Tian WS. 1983: Systematic discussion of the genus Batrachuperus with description of a new species (Salamandriformes, Hynobiidae). Acta Zootaxonomica Sinica 8:209-219. (in Chinese with English abstract)

Monath T. 1965. The opercular apparatus of salamanders. Journal of Morphology 116:149-170. DOI: $10.1002 / j m o r .1051160202$.

Morescalchi A. 1973. Amphibia. In: Chiarelli AB, Capanna E, eds. Cytotaxonomy and Vertebrate Evolution. New York and London: Academic Press, 233-348.

Morescalchi A. 1975. Chromosome evolution in the caudate Amphibia. Evolutionary Biology 8:339-387.

Noble GK. 1931. The Biology of the Amphibia. New York and London: McGraw-Hill Book Company.

Okajima K, Tsuaki T. 1921. Beiträge zur Morphologie des Skleralknorpels bei den Urodelen. Zeitschrift für Anatomie und Entwicklungsgeschichte 60: 631-651.

Olson EC. 1966. The middle ear-morphological types in amphibians and reptiles. American Zoologist 6:399-419. DOI: https://doi.org/10.1093/icb/6.3.399. 
1333 Reese AM. 1906. Anatomy of Cryptobranchus allegheniensis. The American Naturalist 40:287-

1334 326. DOI: https://doi.org/10.1086/278619.

1335 Regel ED. 1970. Ascending process of the palatoquadratic cartilage in urodelans. Doklady Akademii Nauk SSSR 194:509-512.

1337 Reilly SM. 1983. The biology of the high altitude salamander Batrachuperus mustersi from Afghanistan. Journal of Herpetology 17:1-9. DOI: 10.2307/1563774.

Reilly SM. 1987. Ontogeny of the hyobranchial apparatus in the salamanders Ambystoma talpoideum (Ambystomatidae) and Notophthalmus viridescens (Salamandridae): the ecological morphology of two neotenic strategies. Journal of Morphology 191:205-214. DOI: $10.1002 /$ jmor.1051910210.

1343 Reilly SM, Altig R. 1996. Cranial ontogeny in Siren intermedia (Caudata: Sirenidae): paedomorphic, metamorphic, and novel patterns of heterochrony. Copeia 1996:29-41. DOI: $10.2307 / 1446939$.

Reilly SM, Lauder G. 1988. Atavisms and the homology of hyobranchial elements in lower vertebrates. Journal of Morphology 195:237-245.

1348 Rose CS. 2003. The developmental morphology of salamander skulls. In: Heatwole H, Davies M, eds. Amphibian Biology. Volume 5: Osteology. Chipping Norton NSW: Surrey Beatty \& Sons, 1684-1781.

1351 Sasaki M. 1924. On a Japanese salamander, in Lake Kutarush, which propagates like the axolotl. Journal of the College of Agriculture, Hokkaido Imperial University 15:1-36.

1353 Sato I. 1943. A Monograph of the Tailed Batrachians of Japan. Osaka: Nippon Shuppan-sha. 1354 Sessions SK. 2008. Evolutionary cytogenetics in salamanders. Chromosome Research 16:1831355 201. DOI:10.1007/s10577-007-1205-3. 
1356 Schmalhausen II. 1958. Nasolacrimal duct and septomaxillare of Urodela. Zoologicheskii Zhurnal 37:570-583.

1358 Schmalhausen II. 1968. The Origin of Terrestrial Vertebrates. New York: Academic Press.

1359 Shubin NH, Wake DB. 2003. Morphological variation, development, and evolution of the limb

1360 skeleton of salamanders. In: Heatwole H, Davies M, eds. Amphibian Biology. Volume 5:

$1361 \quad$ Osteology. New South Wales: Surrey Beatty and Sons, 1782-1808.

1362 Smirnov SV, Vassilieva AB. 2002. Skeletal and dental ontogeny in the long-tailed clawed

1363

1364 salamander, Onychodactylus fischeri (Urodela: Hynobiidae). Russian Journal of Herpetology 9:21-32. URL: http://rjh.folium.ru/index.php/rjh/article/view/590.

1365 Song M, Zeng X, Wu G, Liu Z, Fu J. 2001. A new species of Batrachuperus from northwestern 1366 China. Asiatic Herpetological Research 9:6-8. DOI: 10.5962/bhl.part.15559.

1367 Sparreboom M. 2014. Salamanders of the Old World. Zeist: KNNV Publishing.

1368 Suzuki T. 1932. Development of the brain, nervous system, and cranial skeleton in amphibians. Anatomica Japonica) 5:685-719.

1371
Trueb L. 1993. Patterns of cranial diversity among the Lissamphibia. In: Hanken J, Hall BK, eds. The Skull, Volume 2: Patterns of Structural and Systematic Diversity. Chicago: The University of Chicago Press, 255-343.

Trueb L, Cloutier R. 1991. A phylogenetic investigation into the inter- and intrarelationships of the Lissamphibia (Amphibia: Temnospondyli). In: Schultze HP, Trueb L, eds. Origins of the Higher Groups of Tetrapods: Controversy and Consensus. Ithaca and London: Cornell University Press, 223-231. 
1378 Vassilieva AB, Poyarkov NA, Iizuka K. 2013. Pecularities [sic] of bony skeleton development in 1379 Asian clawed salamanders (Onychodactylus, Hynobiidae) related to embryonization.

1380 Biology Bulletin 40:1-11. 589-599. DOI: 10.1134/S1062359013070078.

1381 Vassilieva AB, Lai JS, Yang SF, Chang YH, Poyarkov NA. Jr. 2015. Development of the bony 1382 skeleton in the Taiwan salamander, Hynobius formosanus Maki, 1922 (Caudata:

1383 Hynobiidae): heterochronies and reductions. Vertebrate Zoology 65:117-130.

1384

Wakahara M. 1996. Heterochrony and neotenic salamanders: possible clues for understanding 1385 the animal development and evolution. Zoological Science 13:756-766.

1386

1387

1388 1389

1390

1391

1392

1393

1394 1395

1396

1397

1398

1399

1400

Wake DB. 2001. "Dicamptodon ensatus" (On-line), Digital Morphology. Accessed April 5, 2017 at http://digimorph.org/specimens/Dicamptodon_ensatus/.

Whipple I. 1906. The ypsiloid apparatus of urodeles. The Biological Bulletin 10:255-297.

Worthington RD, Wake DB. 1971. Larval morphology and ontogeny of the ambystomatid salamander, Rhyacotriton olympicus. American Midland Naturalist 85:349-365. DOI: 27 $10.2307 / 2423762$.

Wu C. 1982. External and skeletal anatomy of Meglobatrachus davidianus. Journal of Zoology 17:11-16. (in Chinese)

Wu G, Xie F. 2004. Batrachuperus londongensis. The IUCN Red List of Threatened Species 2004: e.T59084A11867916. http://dx.doi.org/10.2305/IUCN.UK.2004.RLTS.T59084A11867916.en. Downloaded on 01 January 2017.

Xiong JL, Yu P, Zhang JL, Zhu WW, Sun P. 2013a. Vertebral column characteristics of Batrachuperus pinchonii, and discussion on the division of the vertebral column in Urodela. Chinese Journal of Zoology 48:451-456. (in Chinese with English abstract). 
1401 Xiong JL, Sun P, Zhang JL, Liu XY. 2013b. A comparative study of the hyobranchial apparatus 1402 in Hynobiidae (Amphibia: Urodela). Zoology 116:99-105. DOI:

$1403 \quad$ 10.1016/j.zool.2012.10.004.

1404 Zhang F. 1985. On anatomy of the skeletal system of Liua shihi (Liu) (Amphibia: Hynobiidae). 1405 Acta Herpetologica Sinica 4:17-24. (in Chinese with English abstract)

1406 Zhang H, Liu S, Zhao Y, Yang Q. 2009. Skeletal system of Batrachuperus pinchonii. Sichuan 1407 Journal of Zoology 28:412-416. (in Chinese with English abstract)

1408 Zhang P. Chen YQ, Zhou H, Liu Y-F, Wang L, Papenfuss TJ, Wake DB, Qu L-H. 2006.

1409 Phylogeny, evolution, and biogeography of Asiatic salamanders (Hynobiidae).

$1410 \quad$ Proceedings of the National Academy of Sciences of the United States of America

1411 103:7360-7365. DOI: 10.1073/pnas.0602325103.

1412 Zheng Y, Peng R, Kuro-o M, Zeng X. 2011. Exploring patterns and extent of bias in estimating 1413 divergence time from mitochondrial DNA sequence data in a particular lineage: a case 1414 study of salamanders (Order Caudata). Molecular Biology and Evolution 28:2521-2535. 1415 DOI: $10.1093 / \mathrm{molbev} / \mathrm{msr} 072$. 


\section{Figure Captions}

1418

1419 Figure 1. Photographs of ethanol-preserved specimens of Batrachuperus londongensis in dorsal

1420 view: (A) holotype CIB 65I0013/14380; (B) referred specimen CIB 14381; (C) referred

1421 specimen CIB 14504. All topotypic specimens were collected from the type locality Longdong

1422 Stream, Mt. Emei, Sichuan Province, China.

1423

1424 Figure 2. Skull roof of Batrachuperus londongensis: (A) holotype CIB 65I0013/14380; (B) CIB

1425 14381; (C) CIB 14482. Specimens CIB 14381 (B) and CIB 14482 (C) display an incomplete

1426 resorption of palatine. Anatomical abbreviations used in this and other figures see list in

1427 Materials \& Methods.

1428

1429 Figure 3. Lateral view of the skull of Batrachuperus londongensis: (A) holotype CIB

1430 65I0013/14380; (B) CIB 14381; (C) CIB 14482. Specimens CIB 14381 (B) and CIB 14482 (C)

1431 display an incomplete resorption of palatine. All images with squamosal and quadrate removed

1432 to expose the otic capsule. Note the unusual perichondral ossification of the ascending process of

1433 palatoquadrate as a pillar between the parietal and pterygoid anterior to the prootic.

1434

1435 Figure 4. Palatal view of the skull of Batrachuperus londongensis: (A) holotype CIB

1436 65I0013/14380; (B) CIB 14381; (C) CIB 14482. Specimens CIB 14381 (B) and CIB 14482 (C)

1437 display an incomplete resorption of palatine. All specimens show that the two vomers have no

1438 midline contact behind the anteromedial fenestra.

1439 
1440 Figure 5. Mandible of Batrachuperus londongensis: right mandible of CIB 14482 in medial (A)

1441 and lateral (B) views; mandibular arch of CIB 14482 in dorsal (C) and ventral (D) views.

1442

1443 Figure 6. Hyobranchial apparatus of Batrachuperus londongensis: (A) CIB 14499, showing a

1444 neotenic pattern with extra ceratobranchials III and IV; (B) CIB 14504, showing a

1445 postmetamorphic pattern with ceratobranchials III and IV entirely lost by resorption.

1446

1447 Figure 7. Holotype skeleton of Batrachuperus londongensis (CIB 65I0013/14380): 3D

1448 reconstruction of whole body of the holotype skeleton in dorsal (A) and ventral (B) views.

1449

1450 Figure 8. Pectoral girdle and upper arm of Batrachuperus londongensis: CIB 65I0013/14380, left

1451 scapulocoracoid in lateral (A) and lateroventral (B) views; left scapulocoracoid of CIB 14381 in

1452 lateral (C) and lateroventral (D) views; left scapulocoracoid of CIB 14504 in lateral (E) and

1453 lateroventral (F) views; left humerus of CIB 65I0013/14380 in dorsal (G) and ventral (H) views;

1454 right humerus of CIB 14381 in dorsal (I) and ventral (J) views; left humerus of CIB 14504 in

1455 dorsal (K) and ventral (L) views. Note unusual ossification of normally cartilaginous parts of

1456 procoracoid and coracoid in the holotype (A, B) and CIB 14504 (E, F). All images not to scale.

1457

1458 Figure 9. Left forearm of Batrachuperus londongensis: (A) CIB 14381; (B) CIB 14484; (C) CIB

1459 14487; (D) CIB 14507. All images display presence of direct contact of the centrale with radius 1460 as an unusual feature in urodeles. All in dorsal view and not to scale. 
1462 Figure 10. Pelvis and femur of Batrachuperus londongensis: Pelvis of CIB 65I0013/14380 in

1463 right lateral (A) and ventral (B) views; pelvis of CIB 14381 in right lateral (C) and ventral (D)

1464 views; pelvis of CIB 14482 in right lateral (E) and ventral (F) views; pelvis of CIB 14487 in

1465 right lateral $(\mathrm{G})$ and ventral $(\mathrm{H})$ views; left femur of CIB 65I0013/14380 in dorsal (I) and ventral

1466 (J) views; left femur of CIB 14381 in dorsal (K) and ventral (L)views; left femur of CIB 14482

1467 in dorsal (M) and ventral (N) views; left femur of CIB 14487 in dorsal (O) and ventral (P) views.

1468 All images not to scale.

1469

1470 Figure 11. Lower hind limb of Batrachuperus londongensis: (A) left lower hind limb of CIB

1471 65I0013/14380; (B) left lower hind limb of CIB 14381; (C) left lower hind limb of CIB 14482;

1472 (D) left lower hind limb of CIB 14487. All in dorsal view and not to scale.

1473

1474 Table 1. Measurements of specimens used in this study. 


\section{Figure 1}

Photographs of ethanol-preserved specimens of Batrachuperus londongensis in dorsal view

(A) holotype CIB 65I0013/14380; (B) referred specimen CIB 14381; (C) referred specimen CIB 14504. All topotypic specimens were collected from the type locality Longdong Stream, Mt. Emei, Sichuan Province, China.
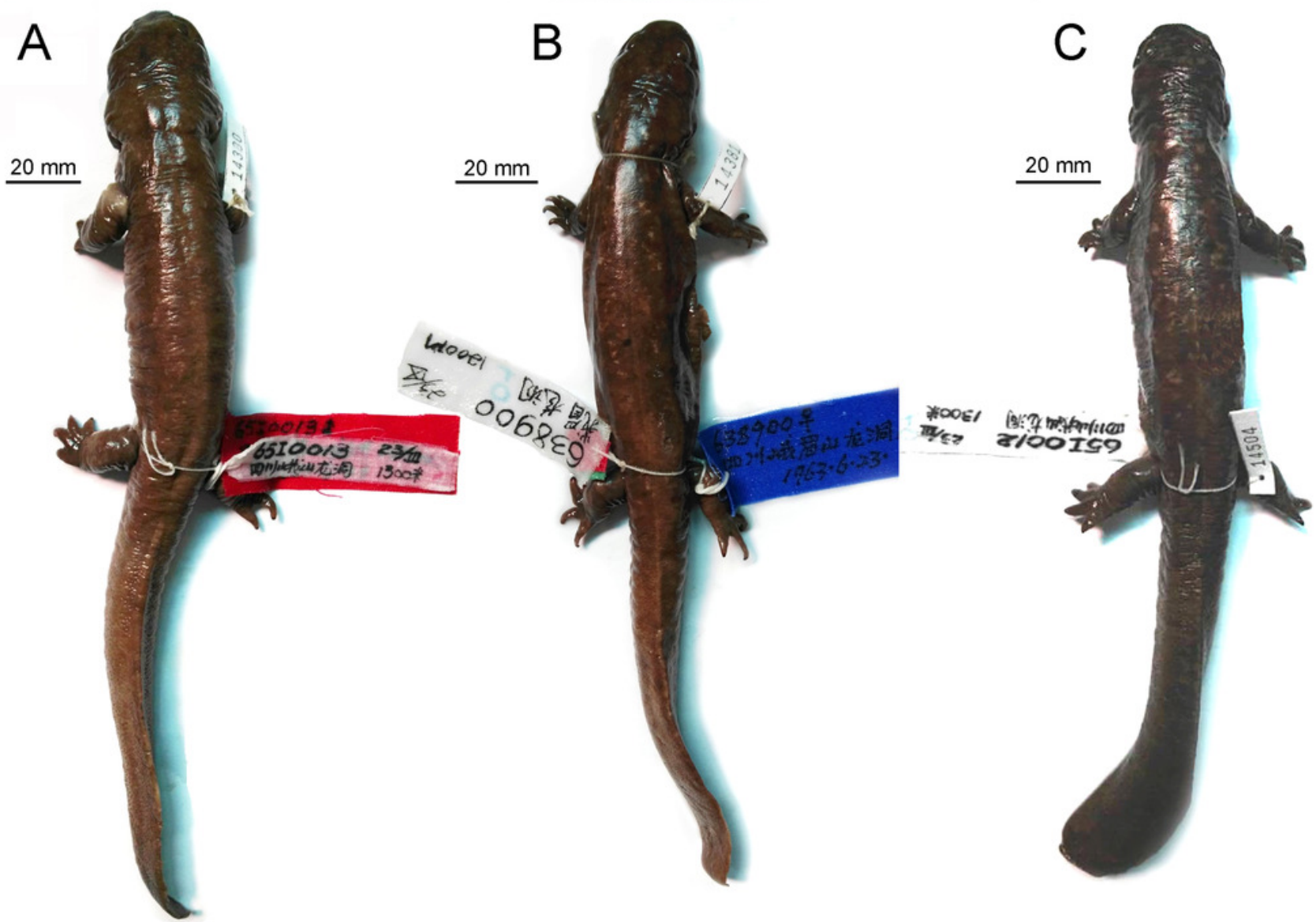


\section{Figure 2}

Skull roof of Batrachuperus londongensis

(A) holotype CIB 65I0013/14380; (B) CIB 143481 (B); (C) CIB 14482. Note Specimens CIB

14381 (B) and CIB 14482 in (C) displaying display an incomplete resorption of palatine.

Anatomical abbreviations used in this and other figures see list in Materials \& Methods.

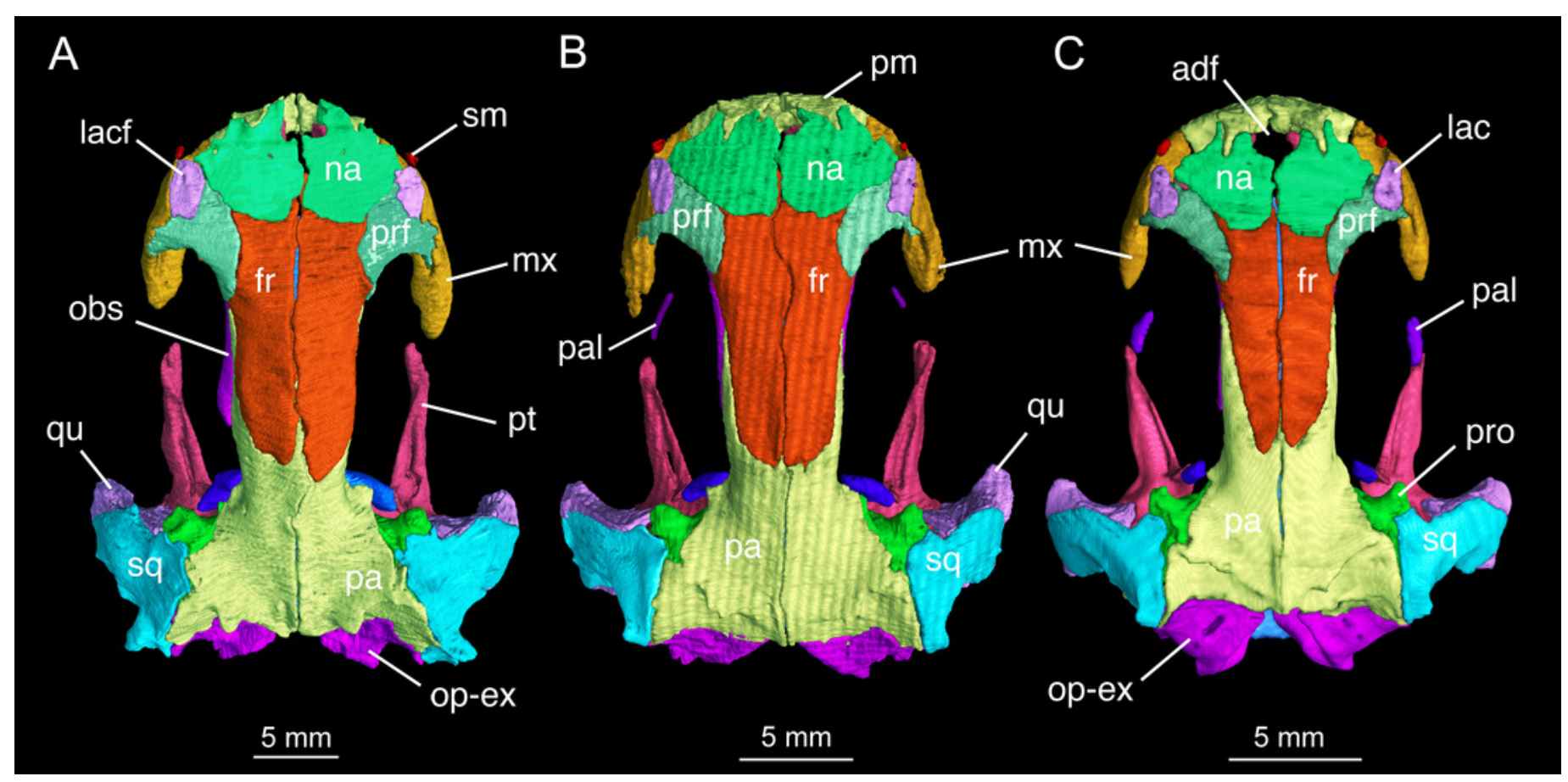




\section{Figure 3}

Lateral view of the skull of Batrachuperus londongensis

(A) CIB holotype CIB 65I0013/14380; (B) CIB 143481; (C) CIB 14482. Specimens CIB 14381

(B) and CIB 14482 (C) display an incomplete resorption of palatine. All images with

squamosal and quadrate removed to expose the otic capsule. Note the unusual perichondral ossification of the ascending process of palatoquadrate as a pillar between the parietal and pterygoid anterior to the prootic.

*Note: Auto Gamma Correction was used for the image. This only affects the reviewing manuscript. See original source image if needed for review.

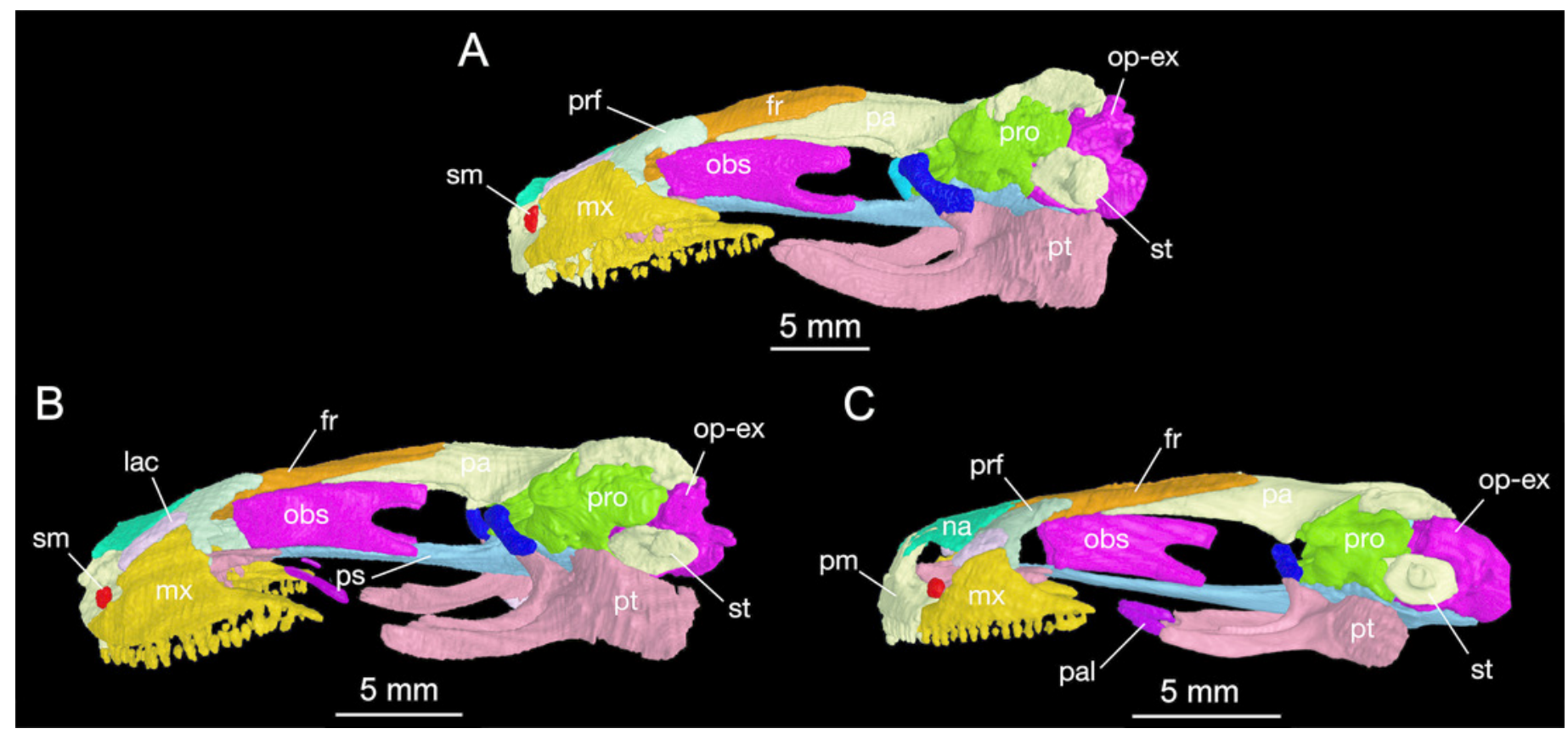




\section{Figure 4}

Palatal view of the skull of Batrachuperus londongensis

(A) holotype CIB 65I0013/14380; (B) CIB 143481; (C) CIB 14482. Specimens CIB 14381 (B)

and CIB 14482 (C) display an incomplete resorption of palatine. NoteAll specimens show that the two vomers have no midline contact behind the anteromedial fenestra.; note also delayed resorption of palatine in CIB 14482 (C).

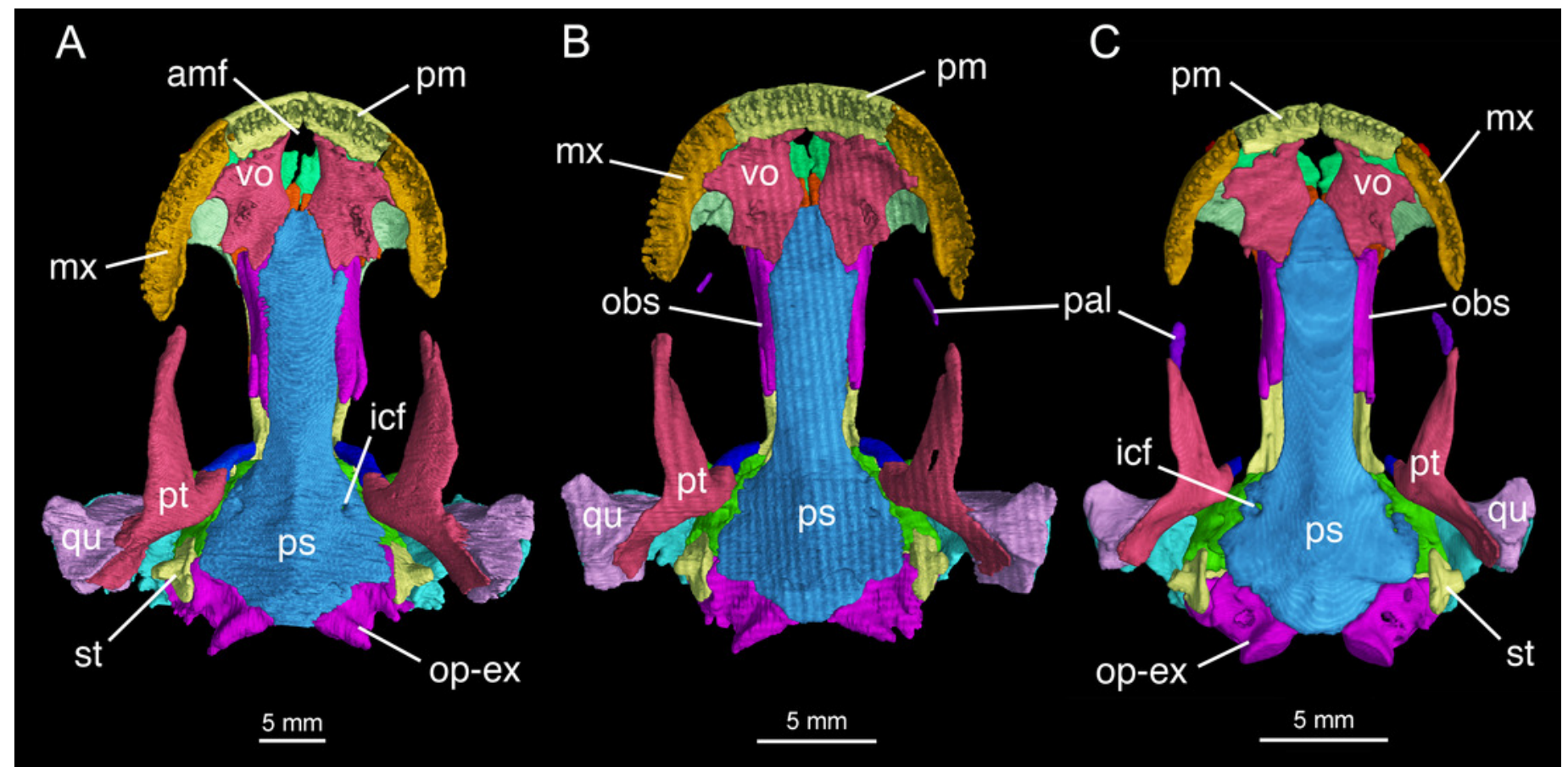




\section{Figure 5}

\section{Mandible of Batrachuperus londongensis}

Right mandible of CIB 14482 in medial (A) and lateral (B) views; mandibular arch of CIB 14482 in dorsal (C) and ventral (D) views.

*Note: Auto Gamma Correction was used for the image. This only affects the reviewing manuscript. See original source image if needed for review. 
A

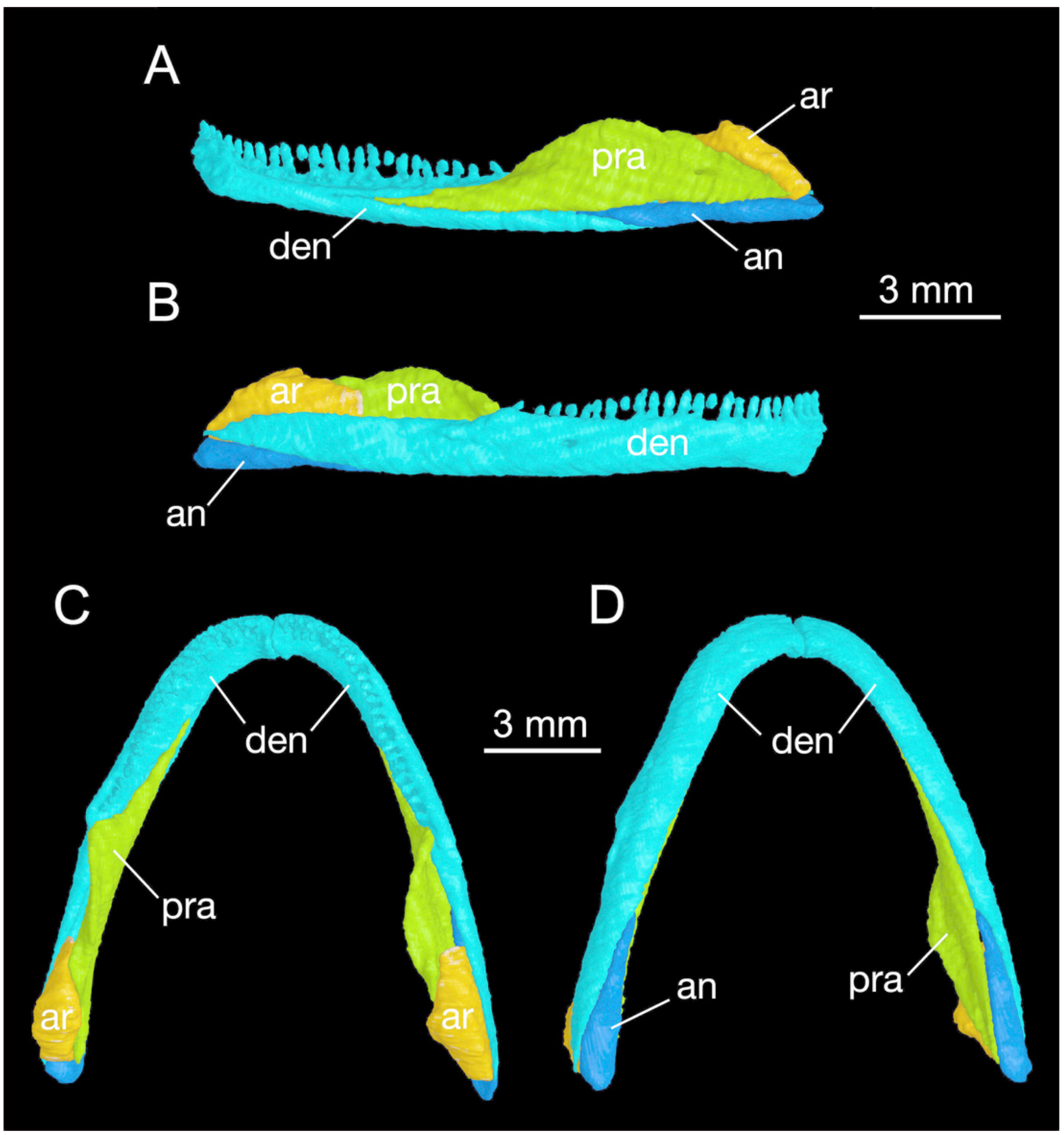


Figure 6

Hyobranchial apparatus of Batrachuperus londongensis

(A) CIB 14499, showing a neotenic pattern with extra ceratobranchials III and IV; (B) CIB 14504, showing a postmetamorphic pattern with ceratobranchials III and IV entirely lost by resorption.

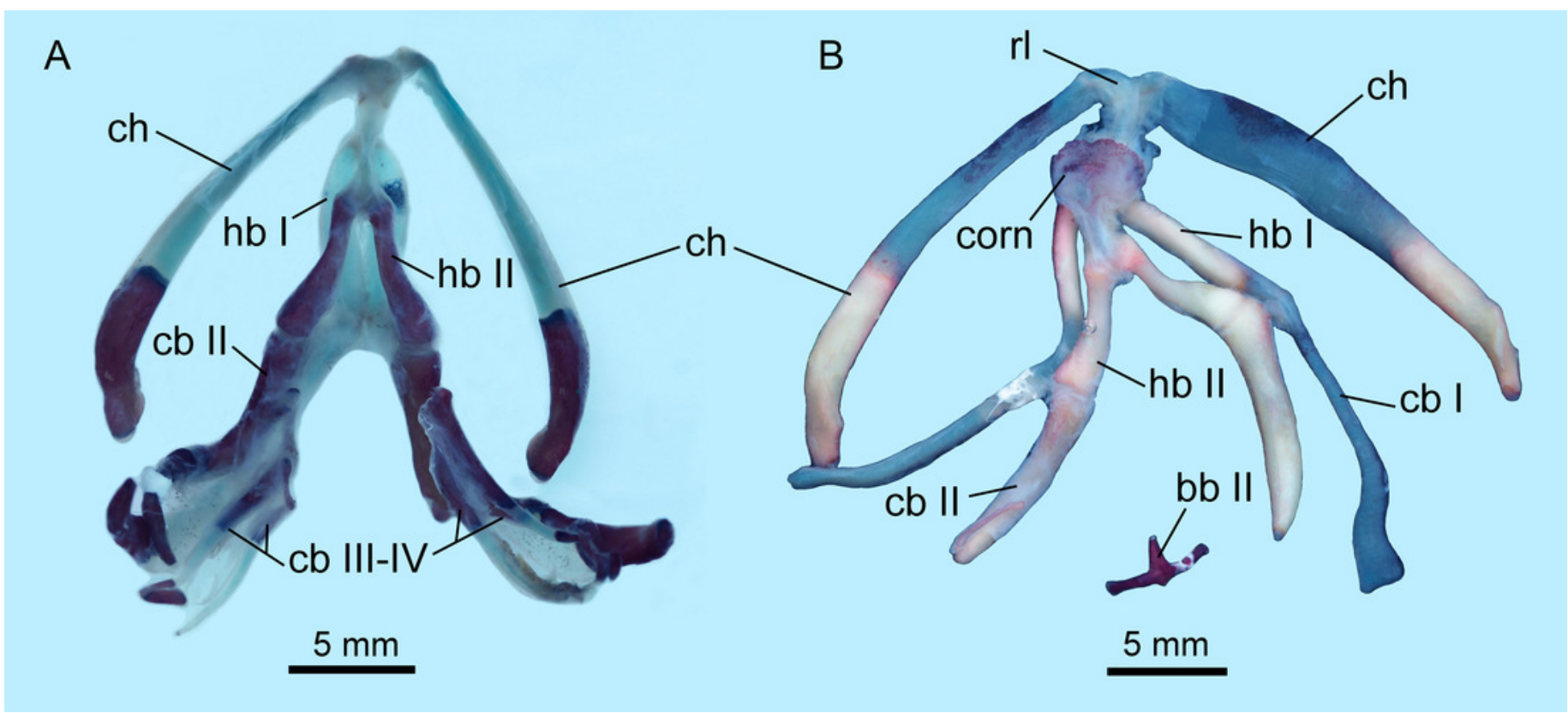




\section{Figure 7}

Holotype skeleton of Batrachuperus londongensis (CIB 65I0013/14380)

$3 \mathrm{D}$ reconstruction of whole body of the holotype skeleton in dorsal $(\mathrm{A})$ and ventral $(\mathrm{B})$ views.

*Note: Auto Gamma Correction was used for the image. This only affects the reviewing manuscript. See original source image if needed for review. 
A
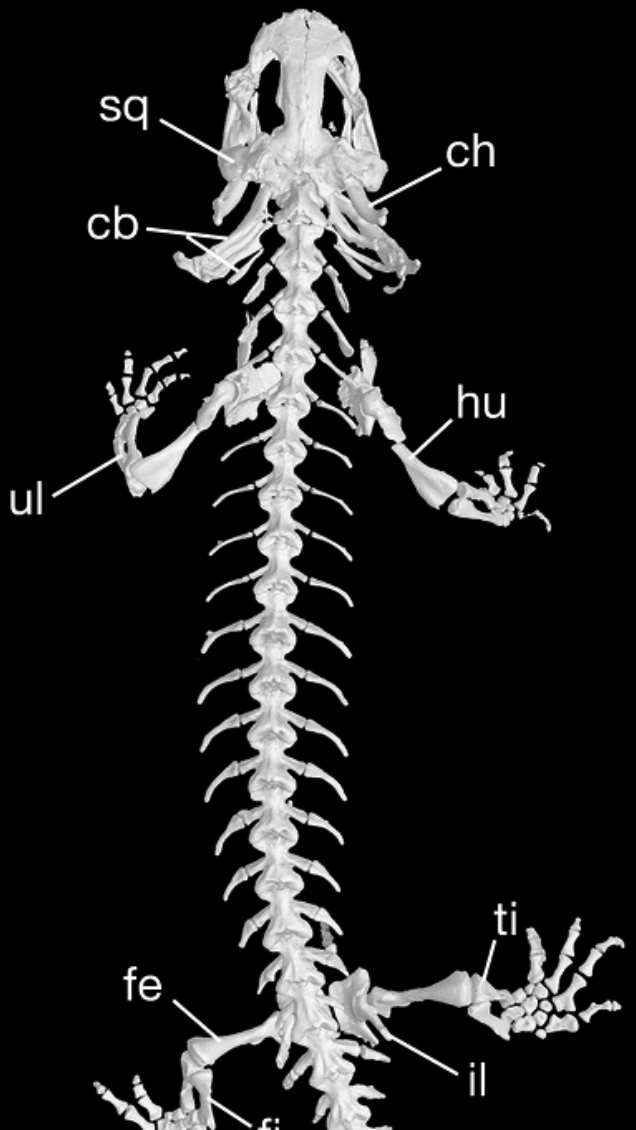

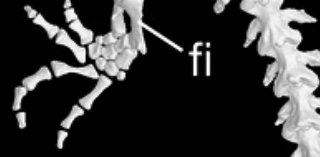




\section{Figure 8}

Pectoral girdle and upper arm of Batrachuperus londongensis

CIB 65I0013/14380, left scapulocoracoid in lateral (A) and lateroventral (B) views; left scapulocoracoid of CIB 14381 in lateral (C) and lateroventral (D) views; left scapulocoracoid of CIB 14504 in lateral (E) and lateroventral (F) views; left humerus of CIB 65I0013/14380 in dorsal (G) and ventral (H) views; right humerus of CIB 14381 in dorsal (I) and ventral (J) views; left humerus of CIB 14504 in dorsal (K) and ventral (L) views. Note unusual ossification of normally cartilaginous parts of procoracoid and coracoid in the holotype $(A, B)$ and $C I B$ $14504(E, F)$. All images not to scale.

*Note: Auto Gamma Correction was used for the image. This only affects the reviewing manuscript. See original source image if needed for review. 


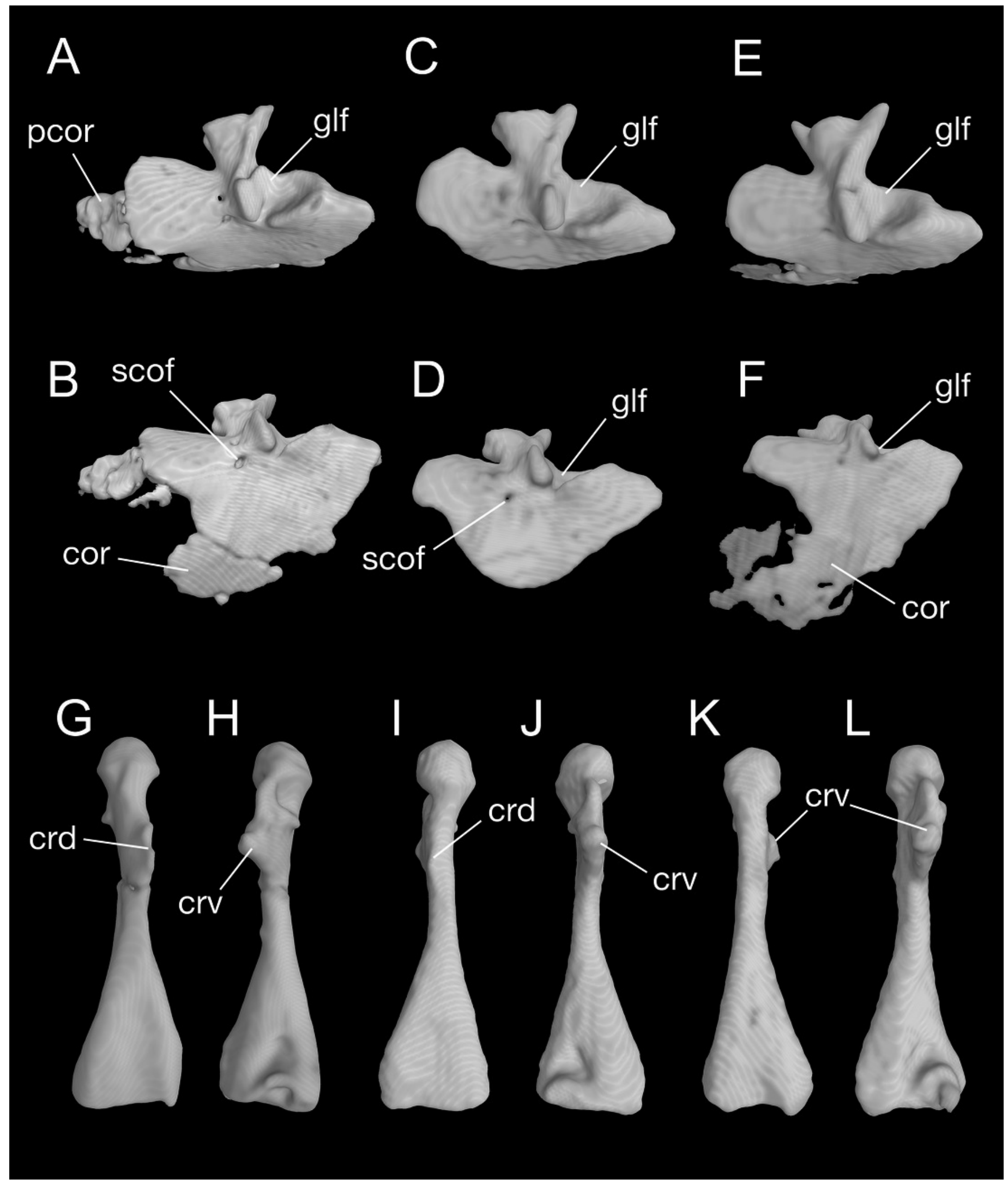




\section{Figure 9}

Left forearm of Batrachuperus londongensis

(A) CIB 14381; (B) CIB 14484; (C) CIB 14487; (D) CIB 14507. All images display presence of direct contact of the centrale with radius as an unusual feature in urodeles. All in dorsal view and not to scale.

*Note: Auto Gamma Correction was used for the image. This only affects the reviewing manuscript. See original source image if needed for review.

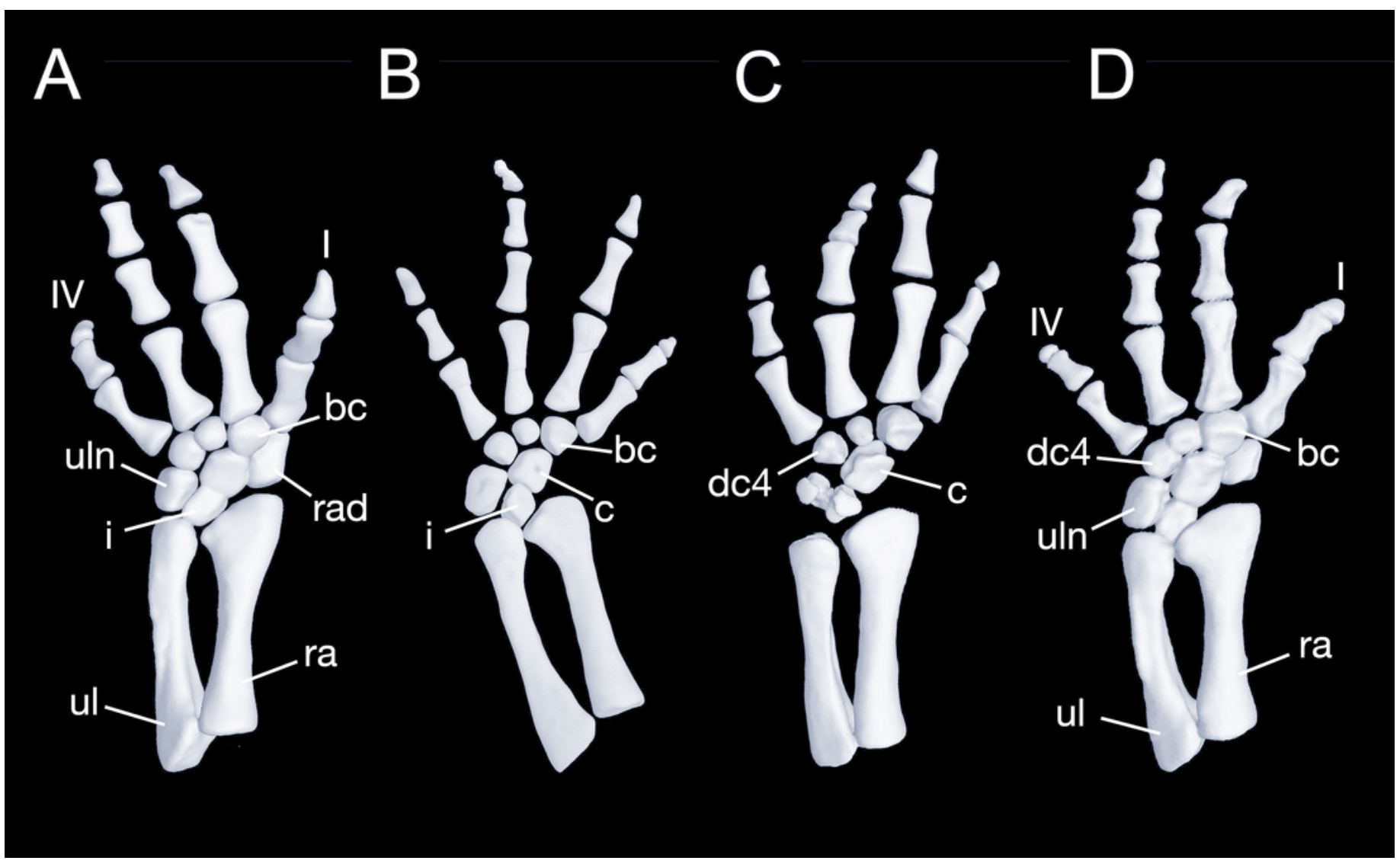




\section{Figure 10}

Pelvis and femur of Batrachuperus londongensis

Pelvis of CIB 65I0013/14380 in right lateral (A) and ventral (B) views; pelvis of CIB 14381 in right lateral (C) and ventral (D) views; pelvis of CIB 14482 in right lateral (E) and ventral (F) views; pelvis of CIB 14487 in right lateral $(G)$ and ventral $(H)$ views; left femur of CIB 65I0013/14380 in dorsal (I) and ventral (J) views; left femur of CIB 14381 in dorsal (K) and ventral (L)views; left femur of CIB 14482 in dorsal (M) and ventral (N) views; left femur of CIB 14487 in dorsal $(O)$ and ventral $(P)$ views. All images not to scale.

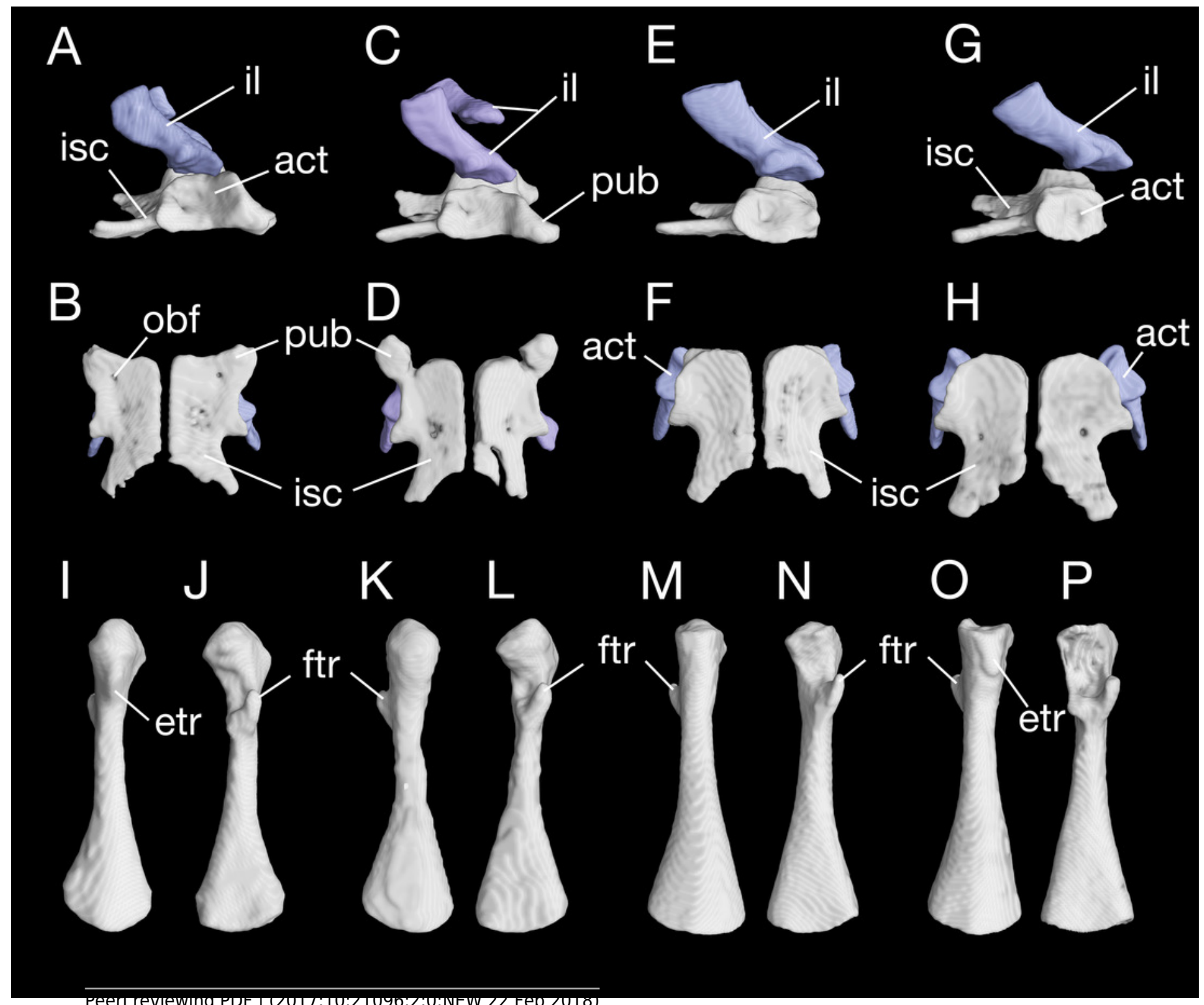




\section{Figure 11}

Lower hind limb of Batrachuperus londongensis

(A) left lower hind limb of CIB 65I0013/14380; (B) left lower hind limb of CIB 14381; (C) left lower hind limb of CIB 14482; (D) left lower hind limb of CIB 14487. All in dorsal view and not to scale.

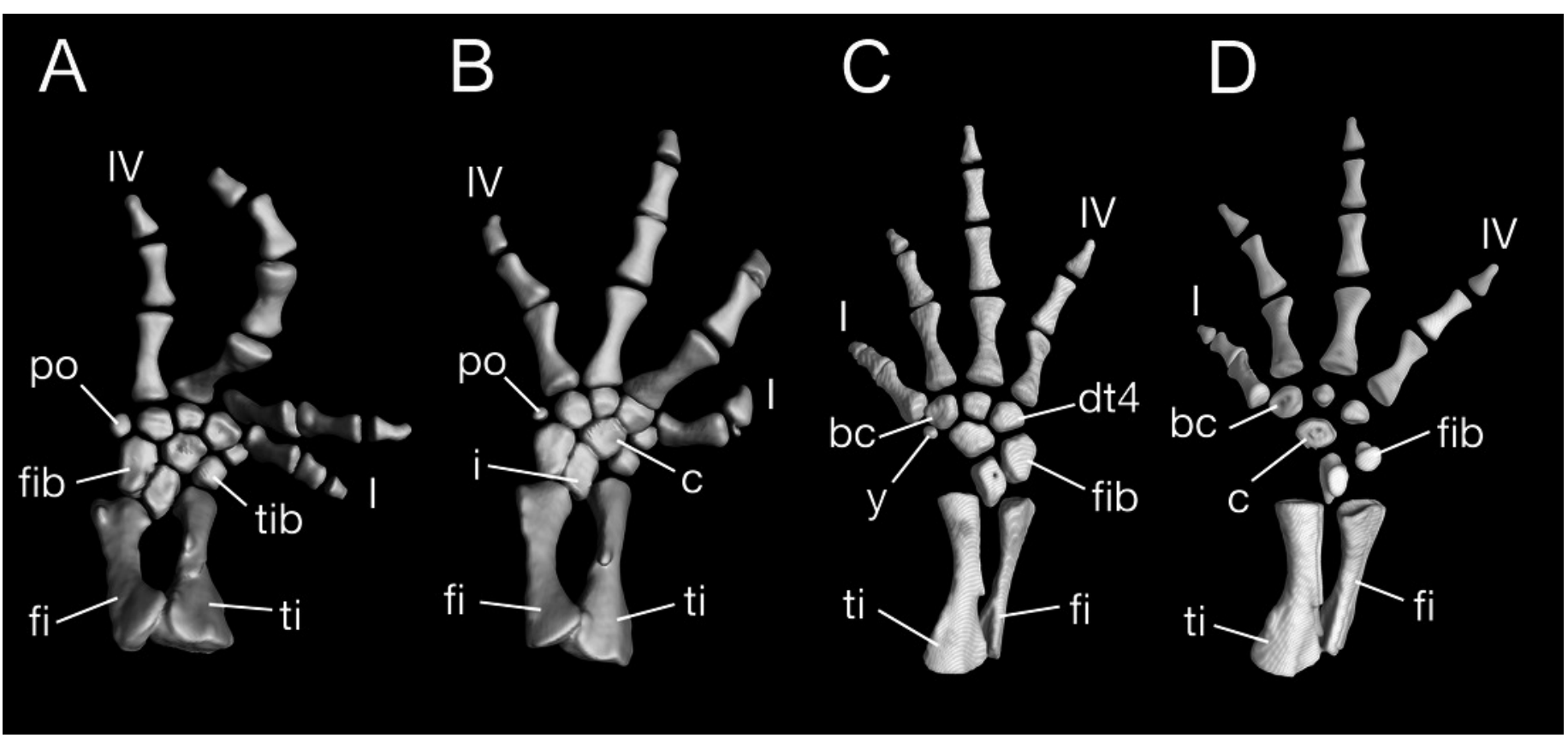




\section{Table 1 (on next page)}

Measurements of specimens used in this study. 


\section{Table 1. Measurements of specimens used in this study}

(Measurements in $\mathrm{mm}$ )

\begin{tabular}{|c|c|c|c|c|c|c|c|}
\hline Catalogue & Field & Male/ & External & Total & Snout- & Skull & Skull \\
\hline Number & Number & Female & Gill Slits & Length & $\begin{array}{l}\text { Pelvic } \\
\text { Length }\end{array}$ & Length & Width \\
\hline CIB 14500 & III I00202 & juvenile & absent & 110.07 & 60.24 & 16.84 & 12.82 \\
\hline CIB 14504 & $65 \mathrm{I} 0012$ & 오 & absent & 220.15 & 117.51 & 26.96 & 21.28 \\
\hline CIB 14507 & 620593 & 0 & absent & 225.35 & 120.32 & 34.08 & 25.69 \\
\hline CIB 14509 & 638866 & 오 & absent & 219.99 & 113.15 & 28.19 & 23.08 \\
\hline CIB 14380 & $65 \mathrm{I} 0013$ & 0 & present & 265.00 & 129.00 & 27.50 & 23.80 \\
\hline CIB14381 & 638900 & 오 & present & 221.94 & 121.00 & 22.70 & 20.00 \\
\hline CIB 14482 & 99I0511 & 운 & present & 178.28 & 98.10 & 25.94 & 17.38 \\
\hline CIB 14484 & 99I 0517 & 0 & present & 189.05 & 97.93 & 26.73 & 18.35 \\
\hline CIB 14485 & 9910520 & 오 & present & 179.39 & 93.92 & 25.35 & 17.77 \\
\hline CIB 14487 & 99I0513 & 0 & absent & 164.09 & 89.27 & 24.38 & 17.51 \\
\hline CIB 14499 & ॥ I00196 & $q$ & present & 214.76 & 116.96 & 27.85 & 21.31 \\
\hline
\end{tabular}

